\title{
Splicing factor mutations in the myelodysplastic syndromes: target genes and therapeutic approaches
}

Richard N. Armstrong*, Violetta Steeples*, Shalini Singh, Andrea Sanchi, Jacqueline Boultwood\#, Andrea Pellagatti\#

Bloodwise Molecular Haematology Unit, Nuffield Division of Clinical Laboratory Sciences, Radcliffe Department of Medicine, University of Oxford, and Oxford BRC Haematology Theme, Oxford, UK

* These authors have contributed equally

\section{\# Corresponding authors:}

Andrea Pellagatti and Jacqueline Boultwood

Nuffield Division of Clinical Laboratory Sciences, Radcliffe Department of Medicine, University of Oxford

John Radcliffe Hospital

Oxford OX3 9DU

United Kingdom

Telephone: +44 1865220480

Fax Number: +44 1865221778

Email: andrea.pellagatti@ndcls.ox.ac.uk and jacqueline.boultwood@ndcls.ox.ac.uk 


\section{$\underline{\text { Abstract }}$}

Mutations in splicing factor genes (SF3B1, SRSF2, U2AF1 and ZRSR2) are frequently found in patients with myelodysplastic syndromes (MDS), suggesting that aberrant spliceosome function plays a key role in the pathogenesis of MDS. Splicing factor mutations have been shown to result in aberrant splicing of many downstream target genes. Recent functional studies have begun to characterize the splicing dysfunction in MDS, identifying some key aberrantly spliced genes that are implicated in disease pathophysiology. These findings have led to the development of therapeutic strategies using splicing-modulating agents and rapid progress is being made in this field. Splicing inhibitors are promising agents that exploit the preferential sensitivity of splicing factor-mutant cells to these compounds. Here, we review the known target genes associated with splicing factor mutations in MDS, and discuss the potential of splicing-modulating therapies for these disorders.

Keywords: Myelodysplastic syndromes; splicing factor genes; mutations; RNA splicing; splicing inhibitors; antisense oligonucleotides 


\section{Introduction}

The myelodysplastic syndromes (MDS) are a heterogeneous group of myeloid malignancies, characterized by ineffective hematopoiesis leading to peripheral blood cytopenias (Heaney and Golde, 1999; Jhanwar, 2015; Pellagatti and Boultwood, 2015; Tefferi and Vardiman, 2009). MDS patients show increasing numbers of malignant myeloid blasts in the bone marrow during the course of the disease. Up to $40 \%$ of MDS cases will progress to acute myeloid leukemia (AML) (Heaney and Golde, 1999; Jhanwar, 2015; Pellagatti and Boultwood, 2015; Tefferi and Vardiman, 2009). The incidence of MDS is similar to that of de novo AML, with approximately 4-5 new cases per 100,000 per year. The incidence increases markedly with age, reaching 30-60 per 100,000 per year in people >70 years old (Howlader et al.; Ma, 2012). MDS patient survival and time to AML evolution are variable; the median overall survival ranges from 0.8 to 8.8 years for very high-risk and very low-risk MDS patients respectively, according to the revised International Prognostic Scoring System (Greenberg et al., 2012).

There are few effective treatments for MDS (Blum, 2016; Chamseddine et al., 2016; Fenaux et al., 2009; List et al., 2006; Steensma, 2015). Existing treatments include erythropoiesisstimulating agents (such as erythropoietin) and lenalidomide for low-risk MDS, and DNA hypomethylating agents (such as azacitidine and decitabine) and traditional chemotherapy for high-risk MDS (Santini, 2017). Allogeneic hematopoietic stem cell transplantation is the only curative option for MDS (de Witte et al., 2017), however few patients are eligible for this treatment. More effective and targeted treatments are clearly needed for MDS.

Next-generation sequencing-based studies have identified several mutated genes in MDS, illuminating the complex mutational landscape of this disorder (Graubert et al., 2011; Haferlach et al., 2014; Makishima et al., 2012; Papaemmanuil et al., 2013; Walter et al., 2013; Yoshida et al., 2011). Mutations in genes involved in pre-mRNA splicing (SF3B1, SRSF2, U2AF1 and ZRSR2) are the most frequent, occurring in more than half of MDS patients (Haferlach et al., 2014; Papaemmanuil et al., 2013). Splicing factor mutations in MDS are typically mutually exclusive and are heterozygous in nature (Damm et al., 2012b; Haferlach et al., 2014; Papaemmanuil et al., 2013; Yoshida et al., 2011). SF3B1, SRSF2 and $U 2 A F 1$ mutations are considered to be change-of-function/neomorphic or gain-of-function due to the presence of hotspots and the absence of frameshift or nonsense variants, while ZRSR2 mutations are distributed across the entire length of the coding region and are loss-offunction (Papaemmanuil et al., 2011; Yip et al., 2016; Yoshida et al., 2011). These mutations are strongly associated with the MDS phenotype and have a much lower prevalence in other hematological malignancies, including de novo AML (Damm et al., 2012a; Haferlach et al., 2014; Hou et al., 2016; Papaemmanuil et al., 2013; Rose et al., 2015; Yoshida et al., 2011). Other commonly mutated genes in MDS are involved in DNA methylation (TET2, DNMT3A, IDH1 and IDH2) and chromatin modification (ASXL1 and EZH2) (Haferlach et al., 2014; Jhanwar, 2015; Papaemmanuil et al., 2013; Pellagatti and Boultwood, 2015).

Splicing factor mutations are considered to be founder mutations in MDS (Mian et al., 2015; Mian et al., 2013). Several studies, including some involving the analysis of serial bone marrow samples, have shown that mutations in splicing factors and epigenetic regulators are typically early events in MDS, while mutations in transcriptional regulators and signal transduction genes are typically late events and are associated with disease evolution (Haferlach et al., 2014; Mossner et al., 2016; Papaemmanuil et al., 2013; Pellagatti et al., 2016). 
Pre-mRNA splicing is a fundamental process required for the expression of most genes (Boultwood et al., 2014; Hoskins and Moore, 2012; Pan et al., 2008). This process is carried out by the major spliceosome, a complex of five small nuclear ribonucleoproteins (snRNPs) $\mathrm{U} 1, \mathrm{U} 2, \mathrm{U} 4, \mathrm{U} 5$ and U6 - and many associated proteins. The formation of the active spliceosome involves an ordered assembly of distinct factors on the pre-mRNA substrate, with the step-wise formation of complexes designated as E, A, B and C (Hoskins and Moore, 2012; Matera and Wang, 2014). The splicing factors that are most frequently mutated in MDS - SF3B1, U2AF1, SRSF2 and ZRSR2 (Haferlach et al., 2014; Papaemmanuil et al., 2013) - form part of the E/A splicing complex that coordinates $3^{\prime}$ splice site recognition during pre-mRNA splicing (Yoshida et al., 2011). It has been shown that mutations of these splicing factors result in aberrant 3' splice site recognition (Pellagatti and Boultwood, 2017; Yoshida et al., 2011), leading to the generation of aberrantly spliced mRNA transcripts in patients with myeloid malignancies with these mutations (Colla et al., 2015; Dolatshad et al., 2015; Dolatshad et al., 2016; Kim et al., 2015; Madan et al., 2015; Pellagatti and Boultwood, 2017; Shirai et al., 2015; Shirai et al., 2017; Yip et al., 2017).

This review describes the most common mutated splicing factor genes in MDS, discussing their role in MDS pathogenesis and highlighting some of the key aberrantly spliced target genes that have been identified. We also discuss the progress and applicability of splicingmodulating agents as potential new treatments for MDS patients harboring splicing factor mutations.

\section{SF3B1}

SF3B1 has been shown to stabilize the U2 snRNP to the branch point sequence during premRNA splicing (Gao et al., 2008; Gozani et al., 1996). Approximately 20-28\% of MDS cases and 19\% of MDS/MPN patients harbor SF3B1 mutations (Haferlach et al., 2014; Malcovati et al., 2011; Papaemmanuil et al., 2011; Papaemmanuil et al., 2013). The prevalence is considerably higher in MDS cases with ring sideroblasts (MDS-RS), with Malcovati et al. showing that SF3B1 mutations positively predict the ring sideroblast (RS) phenotype in $\sim 98 \%$ of cases (Malcovati et al., 2011). This strong correlative evidence suggests a causative link between SF3B1 mutations and a commonly reported dysplastic feature in MDS. An important recent study by Mortera-Blanco et al. showed that NSG mice transplanted with hematopoietic stem cells (HSCs) from SF3B1 mutant MDS-RS patients develop the characteristic ring sideroblasts phenotype (Mortera-Blanco et al., 2017).

Most studies have shown that SF3B1 mutations are predictive of better MDS patient survival and a reduced risk of AML transformation (Malcovati et al., 2015; Malcovati et al., 2011; Papaemmanuil et al., 2011), however some other studies have not made this observation (Damm et al., 2012b; Kang et al., 2015; Lin et al., 2014; Patnaik et al., 2012; Thol et al., 2012). Variables such as age, SF3B1 mutation burden, presence of co-mutations (such as DNMT3A mutations) and different treatment regimens among various cohorts likely account for these differences (Kang et al., 2015; Lin et al., 2014; Malcovati et al., 2015).

SF3B1 mutations in hematological malignancies typically occur in the highly conserved Cterminal domain, between the fourth and eighth HEAT domain repeats (Hahn and Scott, 2011; Papaemmanuil et al., 2013). Approximately half of these missense mutations occur at amino acid residue K700, although there are other nearby hotspots (R625, H662 and K666) that are suspected to have a similar functional impact due to their close spatial proximity 
(Papaemmanuil et al., 2013; Quesada et al., 2011). A number of studies have shown that SF3B1 mutations result in aberrant splicing of target genes via cryptic 3' splice site usage (Darman et al., 2015; DeBoever et al., 2015; Dolatshad et al., 2015; Dolatshad et al., 2016). Aberrant $3^{\prime}$ splice site usage can give rise to premature termination codons in the mRNA, resulting in transcript degradation by nonsense-mediated decay (NMD) and consequent gene down-regulation (Brogna and Wen, 2009; Dolatshad et al., 2016). Most recently, Kesarwani et al. suggested that the $\mathrm{SF} 3 \mathrm{~B} 1{ }^{\mathrm{K} 700 \mathrm{E}}$ mutant protein is able to access cryptic 3 ' splice sites that are typically protected by intronic secondary structures from recognition by wildtype SF3B1, making them available for nucleophilic attack during the splicing process (Kesarwani et al., 2017).

Several studies have identified dysregulated gene isoforms and aberrantly spliced target genes in SF3B1 mutant MDS using RNA-seq (Darman et al., 2015; Dolatshad et al., 2015; Dolatshad et al., 2016; Makishima et al., 2012; Obeng et al., 2016; Visconte et al., 2015; Visconte et al., 2012). The functional characterization of specific target genes of mutant $\mathrm{SF} 3 \mathrm{~B} 1$ is an active area of research.

\subsection{SF3B1 target genes}

\subsection{1 $A B C B 7$}

The mitochondrial iron exporter $A B C B 7$, a well-recognized candidate gene for MDS with the RS phenotype (Boultwood et al., 2008; Nikpour et al., 2013; Pellagatti and Boultwood, 2017), is the most studied target gene that has been shown to be aberrantly spliced in SF3BI mutant MDS (Dolatshad et al., 2016).

Marked down-regulation of $A B C B 7$ in MDS-RS patients was first reported several years ago (Boultwood et al., 2008). This study highlighted a strong relationship between an increasing percentage of ring sideroblasts and decreasing $A B C B 7$ expression levels (Boultwood et al., 2008). Intriguingly, hereditary $X$-linked sideroblastic anemia and ataxia is caused by partial loss-of-function missense mutations of $A B C B 7$ (Allikmets et al., 1999; Bekri et al., 2000; Pondarre et al., 2007). Elegant functional studies subsequently implicated ABCB7 in the phenotype of acquired sideroblastic anemia (RARS) (Nikpour et al., 2013). The integration of mutation and gene expression data in MDS CD34 ${ }^{+}$cells showed a strong association between the presence of $S F 3 B 1$ mutations and $A B C B 7$ down-regulation (Gerstung et al., 2015), thus suggesting a three-way interconnection among $S F 3 B 1$ mutation, $A B C B 7$ down-regulation and the presence of ring sideroblasts. More recently, Dolatshad et al. showed that downregulation of $A B C B 7$ in $S F 3 B 1$ mutant MDS is due to the usage of a cryptic 3' splice site that causes retention of a $21 \mathrm{bp}$ intronic region leading to mRNA degradation by NMD (Dolatshad et al., 2016). Similar findings have recently been described by others in MDS patients with SF3B1 mutations (Malcovati and Cazzola, 2016).

Collectively, these studies support a model in which $A B C B 7$ down-regulation, resulting from aberrant splicing due to $S F 3 B 1$ mutations, underlies the increased mitochondrial iron accumulation observed in MDS patients with RS (Boultwood et al., 2008; Dolatshad et al., 2016; Gerstung et al., 2015; Nikpour et al., 2013). It is important to note that the cryptic 3' splice site identified in the $A B C B 7$ gene is not conserved in mice (Mupo et al., 2017; Obeng et al., 2016), offering a potential explanation for to the lack of ring sideroblasts in $S f 3 b 1^{\mathrm{K} 700 \mathrm{E} /+}$ knock-in as well as $S f 3 b 1^{+/-}$mice (Matsunawa et al., 2014; Mupo et al., 2017; Obeng et al., 2016; Wang et al., 2014). 


\subsubsection{Other SF3B1 target genes}

An early study by Visconte et al. investigated differential exon usage (indicative of alternative splicing) in bone marrow mononuclear cells of SF3B1 mutant MDS patient samples compared to healthy controls and showed differential exon usage in the MDS and/or hematopoiesis-related genes $A S X L 1, C B L, E Z H 1$ and $R U N X 3$ (Visconte et al., 2012).

Several studies have identified cryptic splicing events of genes involved in iron homeostasis and/or hemoglobin biosynthesis in SF3B1 mutant MDS (Conte et al., 2015; Dolatshad et al., 2016; Jin et al., 2017; Visconte et al., 2015). A study by Visconte et al. that focused on the cellular iron phenotypes of SF3B1 mutant patients with RARS with thrombocytosis (RARST), identified a splice variant of SLC25A37 that contained a retained intron and was upregulated in bone marrow mononuclear cells of SF3B1 mutant RARS-T patients compared to wildtype patients and healthy controls (Visconte et al., 2015). SLC25A37 has been suggested to play a role in mitochondrial iron delivery in erythroid cells (Paradkar et al., 2009), and its differential splicing in SF3B1 mutant RARS-T cells may contribute to the RS phenotype in these patients (Visconte et al., 2015). In another study, Conte et al. identified cryptic splicing events in the mitochondrial transporter TMEM14C and the $\alpha$-globin transcription factor $T F C P 2$, both involved in the regulation of erythroid gene expression and hemoglobin biosynthesis (Bosè et al., 2006; Conte et al., 2015; Yien et al., 2014), in CD34 ${ }^{+}$cells from SF3B1 mutant RARS patients (Bosè et al., 2006; Conte et al., 2015; Yien et al., 2014).

Dolatshad et al. identified differentially expressed genes at the transcript and/or exon level in bone marrow $\mathrm{CD}^{+} 4^{+}$cells from SF3B1 mutant MDS patients compared to splicing factor wildtype MDS patients and to healthy controls (Dolatshad et al., 2015). Many of the dysregulated genes identified, including ASXL1, CBL, ALAS2 and SLC25A37, are involved in cellular processes/pathways that are relevant to the known MDS and RARS pathophysiology. Furthermore, some of the aberrantly spliced target genes (CRNDE, TMEM14C and UQCC1) found in this study were previously reported in other cancers harboring $S F 3 B 1$ mutations (Furney et al., 2013; Maguire et al., 2015).

In a subsequent study, Dolatshad et al. used an alternative bioinformatic approach that can identify aberrant/cryptic splicing events, and showed aberrant splicing in key target genes, including ABCC5 and SEPT6, in bone marrow CD34 ${ }^{+}$cells of SF3B1 mutant MDS patients (Dolatshad et al., 2016). Cryptic splicing events were also identified in TMEM14C, ENOSF1, DYNLL1 and HINT2. Interestingly, aberrant splicing of these genes has been reported in association with SF3B1 mutations in other cancers (Ferreira et al., 2014; Furney et al., 2013; Maguire et al., 2015), indicating that there are downstream target genes common to multiple SF3B1 mutant malignancies. Gene ontology analysis showed an enrichment of RNA processing/splicing categories, pointing towards an exacerbation of aberrant pre-mRNA splicing in SF3B1 mutant MDS (Dolatshad et al., 2015).

Obeng et al. compared the aberrant splicing events identified in the myeloid progenitor cells from a Sf3b1 ${ }^{+/ K 700 E}$ knock-in mouse model with those identified in bone marrow mononuclear cells from MDS patients harboring SF3B1 mutations (Obeng et al., 2016). This study showed that mutant SF3B1 causes aberrant 3' splice site selection in both human and mouse cells, however very few aberrantly spliced target genes were common to both data sets, including TOR1AIP2, BAZ2B and SERBP1 (Obeng et al., 2016). It was concluded that the lack of overlapping target genes between the data sets was due to poor conservation of 
intronic sequences between species, highlighting a key limitation of using non-xenograft mouse models in this context.

\section{SRSF2}

SRSF2 is a member of the serine/arginine (SR)-rich family of pre-mRNA splicing factors. During splicing, SRSF2 promotes exon recognition by binding mRNA exonic splicing enhancer (ESE) motifs through its RNA recognition motif domain (RRM). This promotes splice site usage by facilitating the binding of U2AF and U1 snRNP to the upstream $3^{\prime}$ splice site and to the downstream 5' splice site respectively (Chen and Manley, 2009; Graveley and Maniatis, 1998; Liu et al., 2000; Schaal and Maniatis, 1999).

Mutations in SRSF2 occur in $\sim 15 \%$ of MDS patients and are more frequent (40-50\% of cases) in chronic myelomonocytic leukemia (CMML) (Haferlach et al., 2014; Meggendorfer et al., 2012; Papaemmanuil et al., 2013; Patnaik et al., 2013). These mutations predominantly occur at the P95 codon which is in close proximity to the RRM domain of the protein (Meggendorfer et al., 2012; Patnaik et al., 2013). MDS patients harboring SRSF2 mutations typically have poorer overall survival and an increased risk of AML transformation compared to patients with wildtype SRSF2 (Patnaik et al., 2013; Thol et al., 2012; Wu et al., 2012).

During pre-mRNA splicing, SRSF2 has been shown to recognize the binding motifs CCNG and GGNG within exons (Kim et al., 2015; Komeno et al., 2015; Zhang et al., 2015a). Using Srsf $2^{\mathrm{P} 95 \mathrm{H} /+}$ knock-in mice, Kim et al. showed that the mutant Srsf2 has an altered affinity to these motifs, with a preference towards CCNG recognition (Kim et al., 2015). This finding has been subsequently validated in mutant $\mathrm{SRSF}^{\mathrm{P} 95 \mathrm{H} /+} \mathrm{K} 562$ cells generated using CRISPR/Cas9 gene editing, and in MDS-L cells with exogenous expression of mutant SRSF2 ${ }^{\mathrm{P} 95 \mathrm{H}}$ (Komeno et al., 2015; Zhang et al., 2015a).

\subsection{SRSF2 target genes}

\subsubsection{EZH2}

The study by Kim et al. is the most comprehensive to date that has investigated the aberrantly spliced genes associated with SRSF2 mutations (Kim et al., 2015). Using RNA-seq, overlapping aberrantly spliced genes were identified between HSCs and myeloid progenitors from the knock-in SRSF2 ${ }^{\mathrm{P} 95 \mathrm{H} /+}$ mice, and primary samples from CMML and AML patients (Kim et al., 2015). Several of the overlapping target genes identified have a known role in hematological malignancies. Inactivating mutations of the histone methyltransferase gene EZH2 are commonly observed in myeloid disorders (Ernst et al., 2010). Interestingly, SRSF2 mutations promoted the inclusion of a "poison exon" in the mRNA of EZH2, which introduces an in-frame stop-codon that triggers NMD. This finding was pertinent to the observations that loss of Ezh2 in mice can promote myeloid malignancies, including MDS (Mochizuki-Kashio et al., 2015; Sashida et al., 2014), and that EZH2 and SRSF2 mutations typically occur in a mutually exclusive manner in MDS (Bejar et al., 2012; Haferlach et al., 2014; Papaemmanuil et al., 2013). Collectively these findings suggest that SRSF2 mutations may contribute to MDS pathogenesis by down-regulating EZH2. A subsequent study by Zhang et al. showed a subtle increase of EZH2 poison exon inclusion $(\sim 5 \%)$ in CRISPR/Cas9-generated mutant SRSF2 ${ }^{\mathrm{P} 95 \mathrm{H} /+}$ K562 cells (Zhang et al., 2015a). 


\subsubsection{Other SRSF2 target genes}

Other target genes found to be differentially spliced by Kim et al. in SRSF2 mutant cells include BCOR (a recurrently mutated gene in MDS and AML), IKAROS (an important stem cell renewal gene) and CASP8 (an apoptosis regulator) (Kim et al., 2015). Other target genes identified by Zhang et al. in SRSF2 ${ }^{\mathrm{P} 95 \mathrm{H} /+} \mathrm{K} 562$ cells include the tumor suppressor ARMC10 and the tyrosine kinase $F Y N$ (Zhang et al., 2015a).

\section{U2AF1}

$\mathrm{U} 2 \mathrm{AF} 1$ is a member of the SR protein family and a subunit of the U2 snRNP that is responsible for the recognition of the AG dinucleotide in pre-mRNA 3' splice sites (Ruskin et al., 1988; Wu et al., 1999). U2AF1 mutations occur in approximately 7-11\% of MDS patients (Haferlach et al., 2014; Papaemmanuil et al., 2013; Thol et al., 2012; Yoshida et al., 2011). U2AF1 mutations affect almost exclusively one of two codons, S34 and Q157, which are located in separate conserved zinc finger domains (Graubert et al., 2011; Haferlach et al., 2014; Hou et al., 2016; Papaemmanuil et al., 2013; Przychodzen et al., 2013). Some studies have shown an association of $U 2 A F 1$ mutations with shorter MDS patient survival (Bejar et al., 2012; Makishima et al., 2012; Wu et al., 2016; Wu et al., 2013) and also an association with an increased risk of AML transformation (Graubert et al., 2011; Thol et al., 2012; Walter et al., 2013).

U2AF1 S34 and Q157 mutations have both been shown to affect exon splicing, but differ in their effect on the $3^{\prime}$ splice site recognition by U2AF1. Specifically, S34 mutants tend to promote exon inclusion when a cytosine or adenosine is present at the -3 position flanking the 3' splice site AG dinucleotide (Brooks et al., 2014; Ilagan et al., 2015; Okeyo-Owuor et al., 2015; Przychodzen et al., 2013; Yip et al., 2017). In contrast, Q157 mutants affect recognition at the +1 position flanking the $3^{\prime}$ splice site $A G$ dinucleotide, promoting exon inclusion when a guanine is present at this position (Ilagan et al., 2015).

\subsection{U2AF1 target genes}

\subsubsection{H2AFY and STRAP}

A recent study by Yip et al. showed that expression of $U 2 A F 1^{\mathrm{S} 34 \mathrm{~F}}$ in normal human hematopoietic progenitors impairs erythroid differentiation and skews granulomonocytic differentiation towards granulocytes (Yip et al., 2017). RNA-seq of erythroid and granulomonocytic colonies revealed that $U 2 A F 1^{\mathrm{S} 34 \mathrm{~F}}$ altered mRNA splicing of many target genes in a lineage-specific manner. Functional experiments showed that the introduction of the isoform changes identified in the target genes $H 2 A F Y$ (encoding an $\mathrm{H} 2 \mathrm{~A}$ histone variant) and STRAP (encoding serine/threonine kinase receptor-associated protein) recapitulated the phenotypes associated with $U 2 A F 1^{\mathrm{S} 34 \mathrm{~F}}$ expression in erythroid and granulomonocytic cells, suggesting a causal link. Importantly, isoform modulation of $H 2 A F Y$ and STRAP was able to rescue the erythroid differentiation defect in $U 2 A F 1^{\mathrm{S} 34 \mathrm{~F}} \mathrm{MDS}$ cells in vitro (Yip et al., 2017).

\subsubsection{ATG7}

A model for the pathogenic role of $U 2 A F 1^{\mathrm{S} 34 \mathrm{~F}}$ mutations in MDS and other cancers has been proposed by Park et al. (Park et al., 2016). This study showed that stable expression of $U 2 A F 1^{\mathrm{S} 34 \mathrm{~F}}$ in the murine bone marrow $\mathrm{Ba} / \mathrm{F} 3$ cell line results in aberrant selection of 
alternative distal cleavage and polyadenylation (CP) sites during mRNA processing ( $40 \%$ of altered processing events). The consequence of this aberrant process is the generation of mRNAs with altered 3' untranslated regions (UTRs) that may affect transcript regulation by other factors such as miRNAs (Di Giammartino et al., 2011).

Aberrant CP usage in the pre-mRNA of Atg7 was highlighted as an important finding (Park et al., 2016). ATG7 plays an important role in autophagy, and is critical for HSC maintenance (Gomez-Puerto et al., 2016; Mortensen et al., 2011). Atg7 deficient mice have mitochondria dysfunction and impaired hematopoiesis, and develop an MDS-like syndrome (Gonçalves et al., 2015; Komatsu et al., 2005; Mortensen et al., 2011; Wulfert et al., 2008). Aberrant CP usage in the Atg7 mRNA was shown by Park et al. to result in a longer isoform with an alternative 3' UTR and reduced protein expression (Park et al., 2016). Importantly, increased use of the ATG7 distal CP site was seen in primary bone marrow cells of $U 2 A F 1$ mutant MDS and AML patients (Park et al., 2016). Cells expressing $U 2 A F 1^{\mathrm{S} 34 \mathrm{~F}}$ showed defective autophagy associated with mitochondrial dysfunction and increased production of reactive oxygen species, resulting in genomic instability and an increased rate of mutations (Park et al., 2016). This study shed light onto the mechanisms by which U2AF1 mutations could promote disease transformation in myeloid malignancy.

\subsubsection{Other U2AF1 target genes}

Shirai et al. identified several target genes that are differentially spliced in both an inducible transgenic $\mathrm{U} 2 \mathrm{AF} 1^{\mathrm{S} 34 \mathrm{~F}}$ mouse model that displays some MDS-like phenotypes, and in primary AML patient samples (Shirai et al., 2015). Overlapping aberrantly spliced target genes include genes known to be mutated in MDS and other cancers (GNAS, BCOR, KDM6A and PICALM) (Bejar et al., 2011; Borel et al., 2012; Haferlach et al., 2014; Zhang et al., 2015b) and genes involved in stem cell biology (H2AFY and MED24) (Chia et al., 2010; GasparMaia et al., 2013; Zhang et al., 2015a). Other studies have reported aberrant splicing of $H 2 A F Y, G N A S, P I C A L M$ and STRAP in K562 cells expressing $U 2 A F 1^{\mathrm{S} 34 \mathrm{~F}}$ and in $\mathrm{U} 2 \mathrm{AF} 1$ mutant lung adenocarcinoma samples (Brooks et al., 2014; Ilagan et al., 2015; Przychodzen et al., 2013). Similar to SF3B1 mutations, the target genes of mutant U2AF1 have shown an enrichment of RNA splicing and processing genes (Dolatshad et al., 2015; Shirai et al., 2015; Yip et al., 2017), suggesting these mutations may further disrupt RNA splicing.

\section{ZRSR2}

The ZRSR2 gene is located on the $\mathrm{X}$ chromosome and encodes a subunit of the major $\mathrm{U} 2$ and minor U12 spliceosome (Madan et al., 2015; Shen et al., 2010). The minor spliceosome carries out splicing of U12-type introns (Madan et al., 2015; Shen et al., 2010; Tronchère et al., 1997) that represent only $\sim 0.5 \%$ of all human introns (Turunen et al., 2013). ZRSR2 mutations occur in 3-11\% of MDS patients, and almost exclusively in males (Damm et al., 2012a; Haferlach et al., 2014; Papaemmanuil et al., 2013; Yoshida et al., 2011). ZRSR2 mutations may be associated with a higher risk of AML transformation in low-risk MDS (IPSS-low or intermediate-1 subgroups), and with a poorer survival with higher AML transformation risk in MDS patients harboring co-mutations of TET2 (Damm et al., 2012a).

ZRSR2 has been shown to be critical for the normal function of the minor U12 spliceosome (Madan et al., 2015; Shen et al., 2010). In a study by Madan et al., experiments including ZRSR2 knock-down in human leukemia cells and RNA-seq analysis of bone marrow cells 
from ZRSR2 mutant MDS patients, demonstrated that ZRSR2 mutations primarily cause aberrant retention of U12-type introns, with U2-type intron splicing largely unaffected (Madan et al., 2015).

\subsection{ZRSR2 target genes}

The target genes of ZRSR2 mutations in MDS have been investigated in only one study to date. Using gene ontology analysis, Madan et al. identified E2F transcription factors (including E2F1,E2F2,E2F3,E2F4 and E2F6) and several genes involved in the MAPK/ERK pathway (including $M A P K 1, M A P K 3, R A S$ and $R A F$ ) as aberrantly spliced in ZRSR2 mutant MDS samples (Madan et al., 2015). Interestingly, MAPK/ERK signaling has been implicated in MDS and AML pathogenesis (Madan et al., 2015; Steelman et al., 2011).

\section{Splicing inhibitors}

The splicing factor mutations found in myeloid malignancies are typically heterozygous, and only rare cases with co-mutation of two splicing factors have been reported (Papaemmanuil et al., 2013). This indicates that homozygous splicing factor mutations are likely to be lethal to the cell and that cells harboring splicing factor mutations cannot tolerate further perturbation of normal pre-mRNA splicing. Indeed recent studies have demonstrated that the survival of splicing factor mutant cells depends on presence of the wildtype allele (Lee et al., 2016; Zhou et al., 2015). Cells harboring heterozygous splicing factor mutations may therefore be more susceptible to splicing inhibition than wildtype cells.

The assembly of the spliceosome is a complex process that involves over 100 proteins that potentially could be therapeutically targeted with small molecules (Hochleitner et al., 2005; Jurica and Moore, 2003). The best characterized small molecule splicing inhibitors target the SF3b complex. These inhibitors can be grouped in to three generalized families that are based on founding compounds that have structural distinctions: FR901464, pladienolide and herboxidiene (Mizui et al., 2004; Nakajima et al., 1996a; Nakajima et al., 1996b; Sakai et al., 2004a; Sakai et al., 2002b). Analogues of these compounds have been identified or synthesized to improve chemical stability, scalability and therapeutic suitability. A list of relevant splicing inhibitors is provided in Table 1, and selected examples are discussed in this section.

\subsection{FR901464 family}

FR901464 was extracted from Pseudomonas bacteria and was shown to have anti-tumor effects in xenograft mice (Nakajima et al., 1996a; Nakajima et al., 1996b). However, it was only a decade later that FR901464 and its methylated derivative, Spliceostatin A (SSA), were identified as splicing inhibitors (Kaida et al., 2007). A study by Corrionero et al. performed using SSA elucidated the mechanism of these compounds as splicing inhibitors, showing that they prevent the SF3b subcomplex from binding the pre-mRNA, thus preventing the recruitment of U2 snRNP to the $5^{\prime}$ of the branch point, and influencing splicing fidelity by causing inaccurate $3^{\prime}$ splice site selection (Corrionero et al., 2011). Meayamycins, Sudemycins and Thailanstatins are analogous compounds that belong to the FR901464 family of splicing inhibitors (Albert et al., 2009; Fan et al., 2011; Liu et al., 2013a). 


\subsection{Pladienolide and herboxidiene families}

Pladienolides and herboxidiene-based polyketide inhibitors are structurally similar, having originally been isolated from Streptomyces sp. bacteria (Mizui et al., 2004; Sakai et al., 2004a; Sakai et al., 2004b; Sakai et al., 2002a; Sakai et al., 2002b). The pladienolides include pladienolide B, pladienolide D, FD-895 and E7107 (Kanada et al., 2007; Seki-Asano et al., 1994; Villa et al., 2012). The herboxidiene types include GEX1A (herboxidiene), GEX1Q1-5 and 18-deoxyherboxidiene (RQN-18690A). Each of these inhibitor types are believed to be functionally similar to FR901464 and SSA, targeting SF3b and modulating splicing function (Effenberger et al., 2016).

\subsection{Interaction of splicing inhibitors with the SF3b subcomplex}

The mechanism by which splicing inhibitors interact and target SF3B1 within the SF3b subcomplex is incompletely understood. Recently, Teng et al. used site-directed mutagenesis and X-ray crystallography to show that the SF3b members, PHF5A and SF3B1, form a binding pocket that is targeted by splicing inhibitors (Teng et al., 2017). Furthermore, they obtained resistant clones of a human colon cancer cell line, HCT116, by respectively treating in vitro cultures with a sustained concentration of the splicing inhibitors GEX1A or E7107. This identified that PHF5A ${ }^{\mathrm{Y} 36}, \mathrm{SF} 3 \mathrm{~B} 1^{\mathrm{K} 1071}$, SF3B1 ${ }^{\mathrm{R} 1074}$ and SF3B1 ${ }^{\mathrm{V} 1078}$, are key residues for the binding and efficacy of tested splicing inhibitors (GEX1A, E7107, SSA and Sudemycin D6). Mutations in these residues have not been reported in MDS or chronic lymphocytic leukemia (CLL) patients (Haferlach et al., 2014; Hahn and Scott, 2011; Papaemmanuil et al., 2013; Quesada et al., 2011).

\subsection{Therapeutic potential of splicing inhibitors}

Splicing inhibitors are typically effective at inhibiting cancer cell growth at nanomolar concentrations (Hasegawa et al., 2011; Kaida et al., 2007; Kotake et al., 2007; Lagisetti et al., 2013). Several studies have shown that normal cells have greater resistance to splicing inhibitors compared to cancer cells in vitro (Lagisetti et al., 2009; Larrayoz et al., 2016; Xargay-Torrent et al., 2015). Furthermore, doses of splicing inhibitors that kill tumor cells in mouse xenografts have minimal toxicities on the host animal (Kashyap et al., 2015; Lagisetti et al., 2009; Mizui et al., 2004; Nakajima et al., 1996a; Xargay-Torrent et al., 2015). Collectively, these findings support the evaluation of splicing inhibitors in clinical studies in patients with hematological malignancies with splicing factor mutations.

\subsubsection{E7107}

Pre-clinical studies involving the splicing inhibitor E7107 (a synthetic derivative of pladienolide D) have showed potential therapeutic applicability for treating myeloid malignancies harboring splicing factor mutations (Lee et al., 2016; Obeng et al., 2016) . An important study by Lee et al. showed that secondary leukemic Srsf2 ${ }^{\mathrm{P} 95 \mathrm{H} /+}$ mice (transformed by MLL/AF9 over-expression) treated with E7107 exhibited a greatly reduced leukemic burden and longer survival compared to leukemic Srsf $2^{+/+}$mice (Lee et al., 2016). Similarly, mice xenografted with SRSF2 mutant AML patient samples and treated with E7107 showed a significant reduction in leukemic burden compared to mice xenografted with splicing factor wildtype AML samples (Lee et al., 2016). 
E7107 also showed efficacy against Sf3bl mutant cells in vivo. Using mice competitively engrafted with host mouse and either $S f 3 b 1^{\mathrm{K} 700 \mathrm{E} /+}$ or $S f 3 b 1^{+/+}$hematopoietic stem and progenitor cells (HSPCs), Obeng et al. showed that E7107 treatment reduced the percentage of chimerism in $S f 3 b 1^{\mathrm{K} 700 \mathrm{E} /+}$, but not $S f 3 b 1^{+/+}$engrafted mice (Obeng et al., 2016).

To date, two parallel phase I clinical trials, NCT00459823 and NCT00499499, have been performed to evaluate the safety of E7107 treatment in patients with various advanced/metastatic solid tumors (total $n=66$ patients) (Eskens et al., 2013; Hong et al., 2014). However, these trials were suspended when $2 / 26$ patients from the NCT00499499 trial developed severe vision loss that was deemed to be probably related to the E7107 treatment. Similarly, in the NCT00459823 trial, 1/40 patients had vision issues that improved once treatment was stopped and following high-dose corticosteroid treatment. These results highlights the importance of future clinical trials for evaluating the safety and potential therapeutic efficacy of other splicing inhibitors (Lee and Abdel-Wahab, 2016).

\subsubsection{Sudemycins}

Sudemycins have shown encouraging potential for therapeutic application in splicing factor mutant hematological malignancies (Lee and Abdel-Wahab, 2016; Shirai et al., 2017; Xargay-Torrent et al., 2015). Xargay-Torrent et al. showed that cultured peripheral blood cells from CLL patients were significantly more sensitive to cytotoxicity when treated with sudemycins, compared to cells from healthy controls. This sensitivity was significantly increased in cultured CLL samples harboring splicing factor mutations, including SF3B1 mutations (Xargay-Torrent et al., 2015). It was suggested that sudemycin may in part induce cytotoxicity in CLL cells by switching the splicing of $M C L 1$, promoting the expression of a shorter pro-apoptotic isoform (Xargay-Torrent et al., 2015).

Most recently, Shirai et al. showed that treatment of human cord blood CD $34^{+}$cells with sudemycin D6 in vitro resulted in 1,030 differentially expressed genes and, more strikingly, 18,833 dysregulated splicing events (Shirai et al., 2017). This strongly suggests that sudemycins predominantly modify rather than inhibit splicing function. In this study, the leukemia cell lines K562 and OCI-AML3 with induced over-expression of U2AF1 ${ }^{\mathrm{S} 34 \mathrm{~F}}$ showed a greater sensitivity to sudemycin D6 compared to experimental controls (Shirai et al., 2017). Interestingly, experiments in $\mathrm{U} 2 \mathrm{AF} 1^{\mathrm{S} 34 \mathrm{~F}}$ and $\mathrm{U} 2 \mathrm{AF} 1$ wildtype transgenic mice, showed that sudemycin D6 treatment affected splicing in both $U 2 A F 1$ wildtype and mutant cells, with effects seen in treated U2AF1 wildtype cells resembling those in untreated $\mathrm{U} 2 \mathrm{AF} 1^{\mathrm{S} 34 \mathrm{~F}}$ cells (Shirai et al., 2017). This study suggests that the increased sensitivity of mutant $U 2 A F 1$ cells to sudemycin D6 treatment may be due to cumulative aberrant splicing effects caused by drug treatment and mutant U2AF1 (Shirai et al., 2017).

Pathway analysis of dysregulated genes in $\mathrm{U} 2 \mathrm{AF} 1^{\mathrm{S} 34 \mathrm{~F}}$ transgenic mice treated with sudemycin D6, identified an enrichment of genes associated with inflammatory signaling pathways (Shirai et al., 2017). These pathways were also found to be enriched from the analysis of dysregulated genes in Srsf $2^{\mathrm{P} 95 \mathrm{H}}$ mice treated with the splicing inhibitor E7107 (Lee et al., 2016), suggesting that splicing factor mutant-specific phenotypes observed in mice treated with splicing inhibitors may be caused by an altered inflammatory response in mutant cells (Shirai et al., 2017). 


\subsubsection{FD-895 and pladienolide-B}

The pladienolides FD-895 and pladienolide-B have shown efficacy on leukemic cells (Kashyap et al., 2015). Kashyap et al. showed that pladienolide-B and the related compound FD-895 induce apoptosis in CLL cells in vitro compared to normal lymphocytes. This increase in apoptosis may be due to alternative splicing of $M C L 1$ and $B C L 2 L 1$, resulting in an increased generation of pro-apoptotic isoforms of these genes (Kashyap et al., 2015). Surprisingly, sensitivity to pladienolide-B and FD-895 was independent of SF3B1 mutations, and was maintained in therapy-resistant TP53 mutant CLL cells co-cultured with protective stromal cells in vitro (Kashyap et al., 2015).

\subsubsection{H3B-8800}

A novel, orally bioavailable splicing modulator, H3B-8800, has recently been identified (Buonamici et al., 2016). This compound potently binds to SF3b complexes and modulates splicing function. H3B-8800 showed preferential in vitro cell growth inhibition of isogenic AML cell lines with knock-in of $S F 3 B 1^{\mathrm{K} 700 \mathrm{E}}$ or $S R S F 2^{\mathrm{P} 95 \mathrm{H}}$ mutations compared to wildtype counterparts. Furthermore, treatment with H3B-8800 inhibited tumor growth in mice xenografted with $S F 3 B 1^{\mathrm{K} 700 \mathrm{E}}$ knock-in K562 cells and reduced the leukemic burden in mice xenografted with $\mathrm{CD} 34^{+}$cells from $S R S F 2$ mutant CMML patients. Interestingly, RNA-seq analysis of isogenic $S F 3 B 1^{\mathrm{K} 700 \mathrm{E}} \mathrm{K} 562$ cells treated with $\mathrm{H} 3 \mathrm{~B}-8800$ showed that intron retention occurred in several genes that encode spliceosome components, suggesting that the preferential effect of H3B-8800 on splicing factor mutant cells is due to the dependency of these cells on normal pre-mRNA splicing. This study demonstrated the therapeutic potential of $\mathrm{H} 3 \mathrm{~B}-8800$ in patients with myeloid malignancies with splicing factor mutations (Buonamici et al., 2016). A phase I clinical trial (NCT02841540) aiming to explore the safety of H3B-8800 in MDS, AML and CMML patients with splicing factor mutations is under way (Steensma et al., 2017).

\section{Oligonucleotide-based therapeutic approaches}

As more studies identify and characterize the key aberrantly spliced genes associated with splicing factor gene mutations in myeloid malignancy, strategies designed to target specific mRNAs using oligonucleotide-based approaches have attracted interest. We discuss below the potential use of oligonucleotides for targeting spliceosome components or splice variants of interest.

\subsection{Oligonucleotide-directed gene down-regulation}

While the small molecule splicing inhibitors that are currently available target only specific components of the splicing machinery, a large number of spliceosome components could be potentially targeted through oligonucleotide-guided mRNA degradation using RNA interference (RNAi) or antisense oligonucleotides (ASOs). The mechanism of RNAi has been described in detail elsewhere (Wittrup and Lieberman, 2015), but briefly the antisense strand of a double-stranded short interfering RNA (siRNA) with complementary sequence to a mRNA of interest enters the RNA-induced silencing (RISC) complex where it induces cleavage of the target mRNA. RNAi-mediated knockdown of SF3B1 resulted in strikingly reduced colony formation in bone marrow HSPCs from AML patients compared to HSPCs from healthy controls (Crews et al., 2016). Alternatively, a reduction of gene expression can be achieved using single-stranded ASOs that are often stabilized by chemical modifications 
to the backbone and to the nucleotides at each end of the molecule ("gapmers") (Scotti and Swanson, 2016). RNase $H$ interacts with the duplex formed by an ASO and its complementary target mRNA through the unmodified nucleotide sequence and subsequently cleaves the mRNA.

Some clinical trials have been performed to investigate the effects of ASOs in hematological malignancies. The ASO Cenersen targets the tumor suppressor TP53 (Caceres et al., 2013). It has been postulated that intact TP53 functionality may - in the context of chemotherapy protect malignant cells, which can be overcome by Cenersen (Alachkar et al., 2012; Bishop et al., 1996; Cortes et al., 2012). Indeed, small clinical trials have indicated that TP53 inhibition by Cenersen in patients with AML and CLL had no specific toxicity and showed a trend towards a synergistic effect with traditional chemotherapy (Bishop et al., 1996; Cortes et al., 2012; Lanasa et al., 2012).

An ongoing phase I clinical trial (NCT01159028) is investigating the safety and antileukemic properties of BP1001, an ASO that targets GRB2 (Growth factor receptor-bound protein 2, an important protein for cancer cell signaling), in patients with MDS, AML and chronic myeloid leukemia. BP1001 has been well tolerated, with more than half of evaluable patients experiencing $\geq 50 \%$ reduction in peripheral or bone marrow blasts (Ohanian et al., 2016).

\subsection{Targeting aberrantly spliced transcripts with ASOs}

Small molecule inhibitors of the spliceosome and oligonucleotide-guided degradation of mRNAs encoding spliceosome components do not allow for the modulation of specific mRNA isoforms of interest. ASO-based approaches could be used to directly target aberrantly spliced mRNA isoforms associated with splicing factor mutations in MDS. ASOs can be designed to specifically bind regions that are unique to an aberrantly spliced mRNA isoform leading its degradation (Fig. 1A). This approach could be useful to reduce the abundance of aberrantly spliced isoforms which confer a gain or change in protein function.

ASOs can also be used to modulate splicing by preventing the interaction of the spliceosome or splicing regulatory factors with the pre-mRNA through steric hindrance, thus directing the splicing machinery towards the generation of a specific isoform (Daguenet et al., 2015). When used in this context, ASOs are termed splice-switching oligonucleotides (SSOs).

\subsubsection{Modulation of aberrantly spliced target genes using SSOs}

The aberrantly spliced genes identified in myeloid malignancy patients with splicing factor mutations could be targeted using splicing modulation approaches. SSO-based strategies aim to alter the balance between mRNA isoforms and restore their normal relative abundance, or to preferentially express specific isoforms, with potential therapeutic effects (Kole et al., 2012). SSOs must be able to block their target sequence on the mRNA without inducing its degradation. Similarly to the gapmers described above, SSOs are also stabilized by chemical modification to the backbone but also to all nucleotides of the molecule in order to prevent RNase H recruitment and subsequent cleavage of the mRNA (Evers et al., 2015; Scotti and Swanson, 2016).

As described above, a key aberrantly spliced target gene associated with SRSF2 mutations is $E Z H 2$. Increased inclusion of a "poison" exon in EZH2 leads to gene down-regulation (Kim et al., 2015). SSOs designed to bind and mask exonic splicing enhancer (ESE) or intronic 
splicing enhancer (ISE) sequences can prevent the binding of splicing enhancers, hence promoting exon skipping (Fig. 1B). This strategy could be used for splicing modulation of EZH2 using SSOs. Interestingly, the first FDA approved SSO, Eteplirsen, used to treat Duchenne muscular dystrophy (DMD), works through an exon skipping mechanism (Stein and Castanotto, 2017). DMD results from disruption (mainly by deletions) of the open reading frame of the dystrophin gene (Kole and Krieg, 2015; van Deutekom et al., 2007). Eteplirsen induces skipping of exon 51 of the dystrophin gene, restoring the reading frame and allowing expression of a shorter, but partially functional, dystrophin protein. Eteplirsen treatment successfully increased dystrophin expression and improved six-minute walk distance in DMD patients (Aartsma-Rus et al., 2003; Mendell et al., 2016; van Deutekom et al., 2007). It should be noted that Eteplirsen is only suitable to treat $13 \%$ of DMD patients, dependent upon the location and the type of the disruption in the dystrophin gene (Goemans et al., 2011).

Another aberrantly spliced target gene which is associated with SRSF2 mutations is BCOR. Reduced expression of a frame-preserving exon has been identified in BCOR (Kim et al., 2015). SSOs which bind intronic splicing silencers (ISS) and/or exonic splicing silencers (ESS) can enhance exon inclusion (Fig. 1C), and this approach could be used for splicing modulation of BCOR. Nusinersen, the second SSO licensed by the FDA, works through an exon inclusion mechanism and is used for treatment of spinal muscular atrophy (SMA) (Stein and Castanotto, 2017). SMA is a genetic condition caused by loss of SMN1 function resulting in progressive motor neuron degeneration, which leads to paralysis and premature death (Hua et al., 2007). Humans possess a SMN1 paralog, SMN2, which encodes the same protein $(\mathrm{SMN})$. However, SMN2 harbors a silent single base substitution in an ESE which reduces exon 7 inclusion and generates an unstable mRNA isoform (Hua et al., 2007; Scotti and Swanson, 2016). Nusinersen masks an ISS in an intron flanking exon 7 of SMN2, enhancing exon 7 inclusion and resulting in increased levels of the SMN protein, and prolongs the survival of SMA patients (Finkel et al., 2016; Hua et al., 2007; Scotti and Swanson, 2016).

SSOs can also be designed to block access to cryptic splice sites, preventing their recognition by the splicing machinery and hence promoting the usage of the canonical splice site (Fig. 1D).

The use of SSO-based strategies to target key aberrantly spliced genes may be a novel therapeutic approach for MDS with splicing factor mutations.

\subsection{Challenges of ASO/SSO-based therapeutic strategies}

A major challenge of using ASOs (including SSOs) therapeutically is their delivery to the target tissues. When administered systemically, oligonucleotides accumulate in the liver and kidneys and are excreted rapidly (Godfrey et al., 2017; Martin-Armas et al., 2006; McMahon et al., 2002). Chemistry-dependent toxicities of ASOs can include hepatotoxicity, nephrotoxicity, proinflammatory effects and, especially relevant to MDS, thrombocytopenia, hence limiting the tolerated dose (Godfrey et al., 2017). The improvement of the delivery systems for therapeutic ASOs is an area of active research (Juliano, 2016). Nanoparticlebased delivery systems can avoid renal clearance if the particles are larger than the pore size of the glomerular filtration barrier (Kanasty et al., 2013). One of the most efficient ways to direct an ASO to its target cell is by conjugating the ASO or its carrier to a ligand (or antibody) that binds to a cell surface protein that is frequently internalized (Juliano, 2016). For example, transferrin-conjugated nanoparticles have been successfully used in vitro to 
deliver an ASO (targeting ribonucleotide reductase R2 subunit) to AML cell lines and to primary AML patient cells, thereby sensitizing these cells to cytarabine (Jin et al., 2010). An alternative delivery strategy is the use of adeno-associated viral vectors, however this approach may limit the frequency of treatment due to the possibility of an immune response (Godfrey et al., 2017).

Another important consideration is that many aberrantly spliced target genes have been identified in the HSPCs of MDS patients with splicing factor gene mutations (Dolatshad et al., 2016; Pellagatti et al., 2017; Shiozawa et al., 2015; Yip et al., 2017), and these isoforms represent potential targets for SSO approaches. Our current understanding of the role played by these isoforms in MDS pathophysiology is still limited, and efforts are being made to determine which mutation-associated splicing events contribute to the MDS disease phenotype. If only a single or few aberrant isoforms prove to be important, isoform modulation with SSOs could represent a promising treatment strategy (Saez et al., 2017). However, if a larger number of isoforms contribute to the MDS phenotype, the therapeutic benefit of SSOs might be more limited.

\section{Conclusions}

Several studies have investigated the downstream target genes and affected pathways associated with the most common splicing factor mutations in MDS. The use of RNA-seq and $a d$ hoc analysis pipelines has been critical for the identification of aberrantly spliced mRNA isoforms in splicing factor mutant MDS patient samples, as well as in isogenic cell lines and mouse models with these mutations. Extensive RNA-seq studies of HSCs from large MDS patient cohorts are necessary to determine the full complement of aberrantly spliced target genes associated with splicing factor mutations. The analysis of bone marrow cell fractions (erythroid and myeloid precursors) is also required to further investigate lineage-specific aberrant splicing in splicing factor mutant MDS.

The impact of the aberrantly spliced genes identified on hematopoiesis is being investigated, and some functional studies have begun to illuminate the role played by aberrant mRNA isoforms in MDS pathophysiology. Further functional studies are required to fully determine how the aberrantly spliced target genes identified contribute to the MDS phenotype.

Recent pre-clinical studies have shown that splicing inhibitors may have therapeutic potential in MDS and related myeloid malignancies with splicing factor mutations. This has led to rapid clinical interest, with some compounds entering clinical trials. The use of SSOs to modulate splicing of specific mutation-associated splicing events may represent a new targeted therapeutic approach in the treatment of myeloid malignancies with splicing factor mutations.

We await with great interest new developments in this fast moving field of research in the oncoming years.

\section{$\underline{\text { Acknowledgements }}$}

We are grateful to Bloodwise (UK) for support. 


\section{Conflicts of interest}

None. 


\section{References}

Aartsma-Rus, A., Janson, A.A., Kaman, W.E., Bremmer-Bout, M., den Dunnen, J.T., Baas, F., et al., 2003. Therapeutic antisense-induced exon skipping in cultured muscle cells from six different DMD patients. Hum Mol Genet. 12, 907-914.

Alachkar, H., Xie, Z., Marcucci, G., Chan, K.K., 2012. Determination of cellular uptake and intracellular levels of Cenersen (Aezea(®), EL625), a p53 antisense oligonucleotide in acute myeloid leukemia cells. J Pharm Biomed Anal. 71, 228-232.

Albert, B.J., McPherson, P.A., O'Brien, K., Czaicki, N.L., Destefino, V., Osman, S., et al., 2009. Meayamycin inhibits pre-messenger RNA splicing and exhibits picomolar activity against multidrug-resistant cells. Mol Cancer Ther. 8, 2308-2318.

Allikmets, R., Raskind, W.H., Hutchinson, A., Schueck, N.D., Dean, M., Koeller, D.M., 1999. Mutation of a putative mitochondrial iron transporter gene (ABC7) in X-linked sideroblastic anemia and ataxia (XLSA/A). Hum Mol Genet. 8, 743-749.

Bejar, R., Stevenson, K., Abdel-Wahab, O., Galili, N., Nilsson, B., Garcia-Manero, G., et al., 2011. Clinical effect of point mutations in myelodysplastic syndromes. N Engl J Med. 364, 2496-2506.

Bejar, R., Stevenson, K.E., Caughey, B.A., Abdel-Wahab, O., Steensma, D.P., Galili, N., et al., 2012. Validation of a prognostic model and the impact of mutations in patients with lower-risk myelodysplastic syndromes. J Clin Oncol. 30, 3376-3382.

Bekri, S., Kispal, G., Lange, H., Fitzsimons, E., Tolmie, J., Lill, R., et al., 2000. Human ABC7 transporter: gene structure and mutation causing X-linked sideroblastic anemia with ataxia with disruption of cytosolic iron-sulfur protein maturation. Blood. 96, 3256-3264.

Bishop, M.R., Iversen, P.L., Bayever, E., Sharp, J.G., Greiner, T.C., Copple, B.L., et al., 1996. Phase I trial of an antisense oligonucleotide OL(1)p53 in hematologic malignancies. J Clin Oncol. 14, 1320-1326.

Blum, W., 2016. Why the stagnation in effective therapy for MDS? Best Pract Res Clin Haematol. 29, 334-340.

Bonnal, S., Vigevani, L., Valcarcel, J., 2012. The spliceosome as a target of novel antitumour drugs. Nat Rev Drug Discov. 11, 847-859.

Borel, C., Dastugue, N., Cances-Lauwers, V., Mozziconacci, M.J., Prebet, T., Vey, N., et al., 2012. PICALM-MLLT10 acute myeloid leukemia: a French cohort of 18 patients. Leuk Res. 36, 1365-1369.

Bosè, F., Fugazza, C., Casalgrandi, M., Capelli, A., Cunningham, J.M., Zhao, Q., et al., 2006. Functional interaction of CP2 with GATA-1 in the regulation of erythroid promoters. Mol Cell Biol. 26, 3942-3954.

Boultwood, J., Dolatshad, H., Varanasi, S.S., Yip, B.H., Pellagatti, A., 2014. The role of splicing factor mutations in the pathogenesis of the myelodysplastic syndromes. Adv Biol Regul. 54, 153-161.

Boultwood, J., Pellagatti, A., Nikpour, M., Pushkaran, B., Fidler, C., Cattan, H., et al., 2008. The role of the iron transporter ABCB7 in refractory anemia with ring sideroblasts. PLoS One. 3, e1970.

Brogna, S., Wen, J., 2009. Nonsense-mediated mRNA decay (NMD) mechanisms. Nat Struct Mol Biol. 16, 107-113.

Brooks, A.N., Choi, P.S., de Waal, L., Sharifnia, T., Imielinski, M., Saksena, G., et al., 2014. A pan-cancer analysis of transcriptome changes associated with somatic mutations in U2AF1 reveals commonly altered splicing events. PLoS One. 9, e87361.

Buonamici, S., Yoshimi, A., Thomas, M., Seiler, M., Chan, B., Caleb, B., et al., 2016. H3B8800, an Orally Bioavailable Modulator of the SF3b Complex, Shows Efficacy in Spliceosome-Mutant Myeloid Malignancies. Blood. 128, 966. 
Caceres, G., McGraw, K., Yip, B.H., Pellagatti, A., Johnson, J., Zhang, L., et al., 2013. TP53 suppression promotes erythropoiesis in $\operatorname{del}(5 \mathrm{q}) \mathrm{MDS}$, suggesting a targeted therapeutic strategy in lenalidomide-resistant patients. Proc Natl Acad Sci U S A. 110, 16127-16132.

Chamseddine, A.N., Jabbour, E., Kantarjian, H.M., Bohannan, Z.S., Garcia-Manero, G., 2016. Unraveling Myelodysplastic Syndromes: Current Knowledge and Future Directions. Curr Oncol Rep. 18, 4.

Chen, M., Manley, J.L., 2009. Mechanisms of alternative splicing regulation: insights from molecular and genomics approaches. Nat Rev Mol Cell Biol. 10, 741-754.

Chia, N.Y., Chan, Y.S., Feng, B., Lu, X., Orlov, Y.L., Moreau, D., et al., 2010. A genomewide RNAi screen reveals determinants of human embryonic stem cell identity. Nature. 468, 316-320.

Colla, S., Ong, D.S., Ogoti, Y., Marchesini, M., Mistry, N.A., Clise-Dwyer, K., et al., 2015. Telomere dysfunction drives aberrant hematopoietic differentiation and myelodysplastic syndrome. Cancer Cell. 27, 644-657.

Conte, S., Katayama, S., Vesterlund, L., Karimi, M., Dimitriou, M., Jansson, M., et al., 2015. Aberrant splicing of genes involved in haemoglobin synthesis and impaired terminal erythroid maturation in SF3B1 mutated refractory anaemia with ring sideroblasts. Br $\mathrm{J}$ Haematol. 171, 478-490.

Convertini, P., Shen, M., Potter, P.M., Palacios, G., Lagisetti, C., de la Grange, P., et al., 2014. Sudemycin E influences alternative splicing and changes chromatin modifications. Nucleic Acids Res. 42, 4947-4961.

Corrionero, A., Miñana, B., Valcárcel, J., 2011. Reduced fidelity of branch point recognition and alternative splicing induced by the anti-tumor drug spliceostatin A. Genes Dev. 25, 445-459.

Cortes, J., Kantarjian, H., Ball, E.D., Dipersio, J., Kolitz, J.E., Fernandez, H.F., et al., 2012. Phase 2 randomized study of p53 antisense oligonucleotide (cenersen) plus idarubicin with or without cytarabine in refractory and relapsed acute myeloid leukemia. Cancer. 118, 418-427.

Crews, L.A., Balaian, L., Delos Santos, N.P., Leu, H.S., Court, A.C., Lazzari, E., et al., 2016. RNA Splicing Modulation Selectively Impairs Leukemia Stem Cell Maintenance in Secondary Human AML. Cell Stem Cell. 19, 599-612.

Daguenet, E., Dujardin, G., Valcárcel, J., 2015. The pathogenicity of splicing defects: mechanistic insights into pre-mRNA processing inform novel therapeutic approaches. EMBO Rep. 16, 1640-1655.

Damm, F., Kosmider, O., Gelsi-Boyer, V., Renneville, A., Carbuccia, N., Hidalgo-Curtis, C., et al., 2012a. Mutations affecting mRNA splicing define distinct clinical phenotypes and correlate with patient outcome in myelodysplastic syndromes. Blood. 119, 3211-3218.

Damm, F., Thol, F., Kosmider, O., Kade, S., Loffeld, P., Dreyfus, F., et al., 2012b. SF3B1 mutations in myelodysplastic syndromes: clinical associations and prognostic implications. Leukemia. 26, 1137-1140.

Darman, R.B., Seiler, M., Agrawal, A.A., Lim, K.H., Peng, S., Aird, D., et al., 2015. CancerAssociated SF3B1 Hotspot Mutations Induce Cryptic 3' Splice Site Selection through Use of a Different Branch Point. Cell Rep. 13, 1033-1045.

de Witte, T., Bowen, D., Robin, M., Malcovati, L., Niederwieser, D., Yakoub-Agha, I., et al., 2017. Allogeneic hematopoietic stem cell transplantation for MDS and CMML: recommendations from an international expert panel. Blood. 129, 1753-1762.

DeBoever, C., Ghia, E.M., Shepard, P.J., Rassenti, L., Barrett, C.L., Jepsen, K., et al., 2015. Transcriptome sequencing reveals potential mechanism of cryptic 3' splice site selection in SF3B1-mutated cancers. PLoS Comput Biol. 11, e1004105. 
Dehm, S.M., 2013. Test-firing ammunition for spliceosome inhibition in cancer. Clin Cancer Res. 19, 6064-6066.

Di Giammartino, D.C., Nishida, K., Manley, J.L., 2011. Mechanisms and consequences of alternative polyadenylation. Mol Cell. 43, 853-866.

Dolatshad, H., Pellagatti, A., Fernandez-Mercado, M., Yip, B.H., Malcovati, L., Attwood, M., et al., 2015. Disruption of SF3B1 results in deregulated expression and splicing of key genes and pathways in myelodysplastic syndrome hematopoietic stem and progenitor cells. Leukemia. 29, 1798.

Dolatshad, H., Pellagatti, A., Liberante, F.G., Llorian, M., Repapi, E., Steeples, V., et al., 2016. Cryptic splicing events in the iron transporter ABCB7 and other key target genes in SF3B1-mutant myelodysplastic syndromes. Leukemia. 30, 2322-2331.

Effenberger, K.A., Anderson, D.D., Bray, W.M., Prichard, B.E., Ma, N., Adams, M.S., et al., 2014. Coherence between cellular responses and in vitro splicing inhibition for the antitumor drug pladienolide B and its analogs. J Biol Chem. 289, 1938-1947.

Effenberger, K.A., Urabe, V.K., Jurica, M.S., 2017. Modulating splicing with small molecular inhibitors of the spliceosome. Wiley Interdiscip Rev RNA. 8,

Effenberger, K.A., Urabe, V.K., Prichard, B.E., Ghosh, A.K., Jurica, M.S., 2016. Interchangeable SF3B1 inhibitors interfere with pre-mRNA splicing at multiple stages. RNA. 22, 350-359.

Ernst, T., Chase, A.J., Score, J., Hidalgo-Curtis, C.E., Bryant, C., Jones, A.V., et al., 2010. Inactivating mutations of the histone methyltransferase gene $\mathrm{EZH} 2$ in myeloid disorders. Nat Genet. 42, 722-726.

Eskens, F.A., Ramos, F.J., Burger, H., O'Brien, J.P., Piera, A., de Jonge, M.J., et al., 2013. Phase I pharmacokinetic and pharmacodynamic study of the first-in-class spliceosome inhibitor E7107 in patients with advanced solid tumors. Clin Cancer Res. 19, 6296-6304.

Evers, M.M., Toonen, L.J., van Roon-Mom, W.M., 2015. Antisense oligonucleotides in therapy for neurodegenerative disorders. Adv Drug Deliv Rev. 87, 90-103.

Fan, L., Lagisetti, C., Edwards, C.C., Webb, T.R., Potter, P.M., 2011. Sudemycins, novel small molecule analogues of FR901464, induce alternative gene splicing. ACS Chem Biol. $6,582-589$

Fenaux, P., Mufti, G.J., Hellstrom-Lindberg, E., Santini, V., Finelli, C., Giagounidis, A., et al., 2009. Efficacy of azacitidine compared with that of conventional care regimens in the treatment of higher-risk myelodysplastic syndromes: a randomised, open-label, phase III study. Lancet Oncol. 10, 223-232.

Ferreira, P.G., Jares, P., Rico, D., Gómez-López, G., Martínez-Trillos, A., Villamor, N., et al., 2014. Transcriptome characterization by RNA sequencing identifies a major molecular and clinical subdivision in chronic lymphocytic leukemia. Genome Res. 24, 212-226.

Finkel, R.S., Chiriboga, C.A., Vajsar, J., Day, J.W., Montes, J., De Vivo, D.C., et al., 2016. Treatment of infantile-onset spinal muscular atrophy with nusinersen: a phase 2, openlabel, dose-escalation study. Lancet. 388, 3017-3026.

Furney, S.J., Pedersen, M., Gentien, D., Dumont, A.G., Rapinat, A., Desjardins, L., et al., 2013. SF3B1 mutations are associated with alternative splicing in uveal melanoma. Cancer Discov. 3, 1122-1129.

Gao, K., Masuda, A., Matsuura, T., Ohno, K., 2008. Human branch point consensus sequence is yUnAy. Nucleic Acids Res. 36, 2257-2267.

Gaspar-Maia, A., Qadeer, Z.A., Hasson, D., Ratnakumar, K., Leu, N.A., Leroy, G., et al., 2013. MacroH2A histone variants act as a barrier upon reprogramming towards pluripotency. Nat Commun. 4, 1565. 
Gerstung, M., Pellagatti, A., Malcovati, L., Giagounidis, A., Porta, M.G., Jädersten, M., et al., 2015. Combining gene mutation with gene expression data improves outcome prediction in myelodysplastic syndromes. Nat Commun. 6, 5901.

Godfrey, C., Desviat, L.R., Smedsrød, B., Piétri-Rouxel, F., Denti, M.A., Disterer, P., et al., 2017. Delivery is key: lessons learnt from developing splice-switching antisense therapies. EMBO Mol Med. 9, 545-557.

Goemans, N.M., Tulinius, M., van den Akker, J.T., Burm, B.E., Ekhart, P.F., Heuvelmans, N., et al., 2011. Systemic administration of PRO051 in Duchenne's muscular dystrophy. N Engl J Med. 364, 1513-1522.

Gomez-Puerto, M.C., Folkerts, H., Wierenga, A.T., Schepers, K., Schuringa, J.J., Coffer, P.J., et al., 2016. Autophagy Proteins ATG5 and ATG7 Are Essential for the Maintenance of Human CD34(+) Hematopoietic Stem-Progenitor Cells. Stem Cells. 34, 1651-1663.

Gonçalves, A.C., Cortesão, E., Oliveiros, B., Alves, V., Espadana, A.I., Rito, L., et al., 2015. Oxidative stress and mitochondrial dysfunction play a role in myelodysplastic syndrome development, diagnosis, and prognosis: A pilot study. Free Radic Res. 49, 1081-1094.

Gozani, O., Feld, R., Reed, R., 1996. Evidence that sequence-independent binding of highly conserved U2 snRNP proteins upstream of the branch site is required for assembly of spliceosomal complex A. Genes Dev. 10, 233-243.

Graubert, T.A., Shen, D., Ding, L., Okeyo-Owuor, T., Lunn, C.L., Shao, J., et al., 2011. Recurrent mutations in the U2AF1 splicing factor in myelodysplastic syndromes. Nat Genet. 44, 53-57.

Graveley, B.R., Maniatis, T., 1998. Arginine/serine-rich domains of SR proteins can function as activators of pre-mRNA splicing. Mol Cell. 1, 765-771.

Greenberg, P.L., Tuechler, H., Schanz, J., Sanz, G., Garcia-Manero, G., Solé, F., et al., 2012. Revised international prognostic scoring system for myelodysplastic syndromes. Blood. 120, 2454-2465.

Haferlach, T., Nagata, Y., Grossmann, V., Okuno, Y., Bacher, U., Nagae, G., et al., 2014. Landscape of genetic lesions in 944 patients with myelodysplastic syndromes. Leukemia. 28, 241-247.

Hahn, C.N., Scott, H.S., 2011. Spliceosome mutations in hematopoietic malignancies. Nat Genet. 44, 9-10.

Hasegawa, M., Miura, T., Kuzuya, K., Inoue, A., Won Ki, S., Horinouchi, S., et al., 2011. Identification of SAP155 as the target of GEX1A (Herboxidiene), an antitumor natural product. ACS Chem Biol. 6, 229-233.

Heaney, M.L., Golde, D.W., 1999. Myelodysplasia. N Engl J Med. 340, 1649-1660.

Hochleitner, E.O., Kastner, B., Fröhlich, T., Schmidt, A., Lührmann, R., Arnold, G., et al., 2005. Protein stoichiometry of a multiprotein complex, the human spliceosomal U1 small nuclear ribonucleoprotein: absolute quantification using isotope-coded tags and mass spectrometry. J Biol Chem. 280, 2536-2542.

Hong, D.S., Kurzrock, R., Naing, A., Wheler, J.J., Falchook, G.S., Schiffman, J.S., et al., 2014. A phase I, open-label, single-arm, dose-escalation study of E7107, a precursor messenger ribonucleic acid (pre-mRNA) splicesome inhibitor administered intravenously on days 1 and 8 every 21 days to patients with solid tumors. Invest New Drugs. 32, 436444.

Hoskins, A.A., Moore, M.J., 2012. The spliceosome: a flexible, reversible macromolecular machine. Trends Biochem Sci. 37, 179-188.

Hou, H.A., Liu, C.Y., Kuo, Y.Y., Chou, W.C., Tsai, C.H., Lin, C.C., et al., 2016. Splicing factor mutations predict poor prognosis in patients with de novo acute myeloid leukemia. Oncotarget. 7, 9084-9101. 
Howlader, N., Noone, A.M., Krapcho, M., Miller, D., Bishop, K., Kosary, C.L., et al. SEER Cancer Statistics Review, 1975-2014, https://seer.cancer.gov/csr/1975_2014/.

Hua, Y., Vickers, T.A., Baker, B.F., Bennett, C.F., Krainer, A.R., 2007. Enhancement of SMN2 exon 7 inclusion by antisense oligonucleotides targeting the exon. PLoS Biol. 5, e73.

Ilagan, J.O., Ramakrishnan, A., Hayes, B., Murphy, M.E., Zebari, A.S., Bradley, P., et al., 2015. U2AF1 mutations alter splice site recognition in hematological malignancies. Genome Res. 25, 14-26.

Jhanwar, S.C., 2015. Genetic and epigenetic pathways in myelodysplastic syndromes: A brief overview. Adv Biol Regul. 58, 28-37.

Jin, S., Su, H., Tran, N.T., Song, J., Lu, S.S., Li, Y., et al., 2017. Splicing factor SF3B1K700E mutant dysregulates erythroid differentiation via aberrant alternative splicing of transcription factor TAL1. PLoS One. 12, e0175523.

Jin, Y., Liu, S., Yu, B., Golan, S., Koh, C.G., Yang, J., et al., 2010. Targeted delivery of antisense oligodeoxynucleotide by transferrin conjugated $\mathrm{pH}$-sensitive lipopolyplex nanoparticles: a novel oligonucleotide-based therapeutic strategy in acute myeloid leukemia. Mol Pharm. 7, 196-206.

Juliano, R.L., 2016. The delivery of therapeutic oligonucleotides. Nucleic Acids Res. 44, 6518-6548.

Jung, H.J., Kim, Y., Shin, J.Y., Sohng, J.K., Kwon, H.J., 2015. Antiangiogenic activity of herboxidiene via downregulation of vascular endothelial growth factor receptor-2 and hypoxia-inducible factor-1alpha. Arch Pharm Res. 38, 1728-1735.

Jurica, M.S., Moore, M.J., 2003. Pre-mRNA splicing: awash in a sea of proteins. Mol Cell. 12, 5-14.

Kaida, D., Motoyoshi, H., Tashiro, E., Nojima, T., Hagiwara, M., Ishigami, K., et al., 2007. Spliceostatin A targets SF3b and inhibits both splicing and nuclear retention of premRNA. Nat Chem Biol. 3, 576-583.

Kanada, R.M., Itoh, D., Nagai, M., Niijima, J., Asai, N., Mizui, Y., et al., 2007. Total synthesis of the potent antitumor macrolides pladienolide B and D. Angew Chem Int Ed Engl. 46, 4350-4355.

Kanasty, R., Dorkin, J.R., Vegas, A., Anderson, D., 2013. Delivery materials for siRNA therapeutics. Nat Mater. 12, 967-977.

Kang, M.G., Kim, H.R., Seo, B.Y., Lee, J.H., Choi, S.Y., Kim, S.H., et al., 2015. The prognostic impact of mutations in spliceosomal genes for myelodysplastic syndrome patients without ring sideroblasts. BMC Cancer. 15, 484.

Kashyap, M.K., Kumar, D., Jones, H.J., Schwaederlé, M., Ghia, E.M., Villa, R., et al., 2012. Fd-895 and Pladienolide B Inhibit mRNA Splicing and Induce Apoptosis in Chronic Lymphocytic Leukemia. Blood. 120, 3890.

Kashyap, M.K., Kumar, D., Villa, R., La Clair, J.J., Benner, C., Sasik, R., et al., 2015. Targeting the spliceosome in chronic lymphocytic leukemia with the macrolides FD-895 and pladienolide-B. Haematologica. 100, 945-954.

Kesarwani, A.K., Ramirez, O., Gupta, A.K., Yang, X., Murthy, T., Minella, A.C., et al., 2017. Cancer-associated SF3B1 mutants recognize otherwise inaccessible cryptic 3' splice sites within RNA secondary structures. Oncogene. 36, 1123-1133.

Kim, E., Ilagan, J.O., Liang, Y., Daubner, G.M., Lee, S.C., Ramakrishnan, A., et al., 2015. SRSF2 Mutations Contribute to Myelodysplasia by Mutant-Specific Effects on Exon Recognition. Cancer Cell. 27, 617-630.

Kole, R., Krainer, A.R., Altman, S., 2012. RNA therapeutics: beyond RNA interference and antisense oligonucleotides. Nat Rev Drug Discov. 11, 125-140. 
Kole, R., Krieg, A.M., 2015. Exon skipping therapy for Duchenne muscular dystrophy. Adv Drug Deliv Rev. 87, 104-107.

Komatsu, M., Waguri, S., Ueno, T., Iwata, J., Murata, S., Tanida, I., et al., 2005. Impairment of starvation-induced and constitutive autophagy in Atg7-deficient mice. J Cell Biol. 169, 425-434.

Komeno, Y., Huang, Y.J., Qiu, J., Lin, L., Xu, Y., Zhou, Y., et al., 2015. SRSF2 Is Essential for Hematopoiesis, and Its Myelodysplastic Syndrome-Related Mutations Dysregulate Alternative Pre-mRNA Splicing. Mol Cell Biol. 35, 3071-3082.

Kotake, Y., Sagane, K., Owa, T., Mimori-Kiyosue, Y., Shimizu, H., Uesugi, M., et al., 2007. Splicing factor SF3b as a target of the antitumor natural product pladienolide. Nat Chem Biol. 3, 570-575.

Lagisetti, C., Palacios, G., Goronga, T., Freeman, B., Caufield, W., Webb, T.R., 2013. Optimization of antitumor modulators of pre-mRNA splicing. J Med Chem. 56, 10033 10044.

Lagisetti, C., Pourpak, A., Goronga, T., Jiang, Q., Cui, X., Hyle, J., et al., 2009. Synthetic mRNA splicing modulator compounds with in vivo antitumor activity. J Med Chem. 52, 6979-6990.

Lagisetti, C., Yermolina, M.V., Sharma, L.K., Palacios, G., Prigaro, B.J., Webb, T.R., 2014. Pre-mRNA splicing-modulatory pharmacophores: the total synthesis of herboxidiene, a pladienolide-herboxidiene hybrid analog and related derivatives. ACS Chem Biol. 9, 643648.

Lanasa, M.C., Davis, P.H., Datto, M., Li, Z., Gockerman, J.P., Moore, J.O., et al., 2012. Phase II study of cenersen, an antisense inhibitor of $\mathrm{p53}$, in combination with fludarabine, cyclophosphamide and rituximab for high-risk chronic lymphocytic leukemia. Leuk Lymphoma. 53, 218-224.

Larrayoz, M., Blakemore, S.J., Dobson, R.C., Blunt, M.D., Rose-Zerilli, M.J., Walewska, R., et al., 2016. The SF3B1 inhibitor spliceostatin A (SSA) elicits apoptosis in chronic lymphocytic leukaemia cells through downregulation of Mcl-1. Leukemia. 30, 351-360.

Lee, S.C., Abdel-Wahab, O., 2016. Therapeutic targeting of splicing in cancer. Nat Med. 22, 976-986.

Lee, S.C., Dvinge, H., Kim, E., Cho, H., Micol, J.B., Chung, Y.R., et al., 2016. Modulation of splicing catalysis for therapeutic targeting of leukemia with mutations in genes encoding spliceosomal proteins. Nat Med. 22, 672-678.

Lin, C.C., Hou, H.A., Chou, W.C., Kuo, Y.Y., Wu, S.J., Liu, C.Y., et al., 2014. SF3B1 mutations in patients with myelodysplastic syndromes: the mutation is stable during disease evolution. Am J Hematol. 89, E109-115.

List, A., Dewald, G., Bennett, J., Giagounidis, A., Raza, A., Feldman, E., et al., 2006. Lenalidomide in the myelodysplastic syndrome with chromosome $5 q$ deletion. $\mathrm{N}$ Engl $\mathrm{J}$ Med. 355, 1456-1465.

Liu, H.X., Chew, S.L., Cartegni, L., Zhang, M.Q., Krainer, A.R., 2000. Exonic splicing enhancer motif recognized by human SC35 under splicing conditions. Mol Cell Biol. 20, 1063-1071.

Liu, X., Biswas, S., Berg, M.G., Antapli, C.M., Xie, F., Wang, Q., et al., 2013a. Genomicsguided discovery of thailanstatins $\mathrm{A}, \mathrm{B}$, and $\mathrm{C}$ As pre-mRNA splicing inhibitors and antiproliferative agents from Burkholderia thailandensis MSMB43. J Nat Prod. 76, 685693.

Liu, X., Biswas, S., Tang, G.L., Cheng, Y.Q., 2013b. Isolation and characterization of spliceostatin B, a new analogue of FR901464, from Pseudomonas sp. No. 2663. J Antibiot (Tokyo). 66, 555-558.

Ma, X., 2012. Epidemiology of myelodysplastic syndromes. Am J Med. 125, S2-5. 
Madan, V., Kanojia, D., Li, J., Okamoto, R., Sato-Otsubo, A., Kohlmann, A., et al., 2015. Aberrant splicing of U12-type introns is the hallmark of ZRSR2 mutant myelodysplastic syndrome. Nat Commun. 6, 6042.

Maguire, S.L., Leonidou, A., Wai, P., Marchiò, C., Ng, C.K., Sapino, A., et al., 2015. SF3B1 mutations constitute a novel therapeutic target in breast cancer. J Pathol. 235, 571-580.

Makishima, H., Visconte, V., Sakaguchi, H., Jankowska, A.M., Abu Kar, S., Jerez, A., et al., 2012. Mutations in the spliceosome machinery, a novel and ubiquitous pathway in leukemogenesis. Blood. 119, 3203-3210.

Malcovati, L., Cazzola, M., 2016. Recent advances in the understanding of myelodysplastic syndromes with ring sideroblasts. Br J Haematol. 174, 847-858.

Malcovati, L., Karimi, M., Papaemmanuil, E., Ambaglio, I., Jädersten, M., Jansson, M., et al., 2015. SF3B1 mutation identifies a distinct subset of myelodysplastic syndrome with ring sideroblasts. Blood. 126, 233-241.

Malcovati, L., Papaemmanuil, E., Bowen, D.T., Boultwood, J., Della Porta, M.G., Pascutto, C., et al., 2011. Clinical significance of SF3B1 mutations in myelodysplastic syndromes and myelodysplastic/myeloproliferative neoplasms. Blood. 118, 6239-6246.

Martin-Armas, M., Simon-Santamaria, J., Pettersen, I., Moens, U., Smedsrød, B., Sveinbjørnsson, B., 2006. Toll-like receptor 9 (TLR9) is present in murine liver sinusoidal endothelial cells (LSECs) and mediates the effect of CpG-oligonucleotides. J Hepatol. 44, 939-946.

Martinez-Montiel, N., Rosas-Murrieta, N.H., Martinez-Montiel, M., Gaspariano-Cholula, M.P., Martinez-Contreras, R.D., 2016. Microbial and Natural Metabolites That Inhibit Splicing: A Powerful Alternative for Cancer Treatment. Biomed Res Int. 2016, 3681094.

Matera, A.G., Wang, Z., 2014. A day in the life of the spliceosome. Nat Rev Mol Cell Biol. $15,108-121$.

Matsunawa, M., Yamamoto, R., Sanada, M., Sato-Otsubo, A., Shiozawa, Y., Yoshida, K., et al., 2014. Haploinsufficiency of Sf3b1 leads to compromised stem cell function but not to myelodysplasia. Leukemia. 28, 1844-1850.

McMahon, B.M., Mays, D., Lipsky, J., Stewart, J.A., Fauq, A., Richelson, E., 2002. Pharmacokinetics and tissue distribution of a peptide nucleic acid after intravenous administration. Antisense Nucleic Acid Drug Dev. 12, 65-70.

Meggendorfer, M., Roller, A., Haferlach, T., Eder, C., Dicker, F., Grossmann, V., et al., 2012. SRSF2 mutations in 275 cases with chronic myelomonocytic leukemia (CMML). Blood. 120, 3080-3088.

Mendell, J.R., Goemans, N., Lowes, L.P., Alfano, L.N., Berry, K., Shao, J., et al., 2016. Longitudinal effect of eteplirsen versus historical control on ambulation in Duchenne muscular dystrophy. Ann Neurol. 79, 257-271.

Mian, S.A., Rouault-Pierre, K., Smith, A.E., Seidl, T., Pizzitola, I., Kizilors, A., et al., 2015. SF3B1 mutant MDS-initiating cells may arise from the haematopoietic stem cell compartment. Nat Commun. 6, 10004.

Mian, S.A., Smith, A.E., Kulasekararaj, A.G., Kizilors, A., Mohamedali, A.M., Lea, N.C., et al., 2013. Spliceosome mutations exhibit specific associations with epigenetic modifiers and proto-oncogenes mutated in myelodysplastic syndrome. Haematologica. 98, 10581066.

Mizui, Y., Sakai, T., Iwata, M., Uenaka, T., Okamoto, K., Shimizu, H., et al., 2004. Pladienolides, new substances from culture of Streptomyces platensis Mer-11107. III. In vitro and in vivo antitumor activities. J Antibiot (Tokyo). 57, 188-196.

Mochizuki-Kashio, M., Aoyama, K., Sashida, G., Oshima, M., Tomioka, T., Muto, T., et al., 2015. Ezh2 loss in hematopoietic stem cells predisposes mice to develop heterogeneous malignancies in an Ezh1-dependent manner. Blood. 126, 1172-1183. 
Mortensen, M., Soilleux, E.J., Djordjevic, G., Tripp, R., Lutteropp, M., Sadighi-Akha, E., et al., 2011. The autophagy protein Atg7 is essential for hematopoietic stem cell maintenance. J Exp Med. 208, 455-467.

Mortera-Blanco, T., Dimitriou, M., Woll, P.S., Karimi, M., Elvarsdottir, E., Conte, S., et al., 2017. SF3B1-initiating mutations in MDS-RSs target lymphomyeloid hematopoietic stem cells. Blood. 130, 881-890.

Mossner, M., Jann, J.C., Wittig, J., Nolte, F., Fey, S., Nowak, V., et al., 2016. Mutational hierarchies in myelodysplastic syndromes dynamically adapt and evolve upon therapy response and failure. Blood. 128, 1246-1259.

Mupo, A., Seiler, M., Sathiaseelan, V., Pance, A., Yang, Y., Agrawal, A.A., et al., 2017. Hemopoietic-specific Sf3b1-K700E knock-in mice display the splicing defect seen in human MDS but develop anemia without ring sideroblasts. Leukemia. 31, 720-727.

Nakajima, H., Hori, Y., Terano, H., Okuhara, M., Manda, T., Matsumoto, S., et al., 1996a. New antitumor substances, FR901463, FR901464 and FR901465. II. Activities against experimental tumors in mice and mechanism of action. J Antibiot (Tokyo). 49, 1204-1211.

Nakajima, H., Sato, B., Fujita, T., Takase, S., Terano, H., Okuhara, M., 1996b. New antitumor substances, FR901463, FR901464 and FR901465. I. Taxonomy, fermentation, isolation, physico-chemical properties and biological activities. J Antibiot (Tokyo). 49, 1196-1203.

Nikpour, M., Scharenberg, C., Liu, A., Conte, S., Karimi, M., Mortera-Blanco, T., et al., 2013. The transporter ABCB7 is a mediator of the phenotype of acquired refractory anemia with ring sideroblasts. Leukemia. 27, 889-896.

Obeng, E.A., Chappell, R.J., Seiler, M., Chen, M.C., Campagna, D.R., Schmidt, P.J., et al., 2016. Physiologic Expression of Sf3b1(K700E) Causes Impaired Erythropoiesis, Aberrant Splicing, and Sensitivity to Therapeutic Spliceosome Modulation. Cancer Cell. 30, 404417.

Ohanian, M., Ravandi, F., Borthakur, G., Garcia-Manero, G., Andreeff, M., Jabbour, E., et al., 2016. Phase I study of BP1001 (Liposomal Grb2 Antisense) in patients with hematologic malignancies. J Clin Oncol. 34, 7010.

Okeyo-Owuor, T., White, B.S., Chatrikhi, R., Mohan, D.R., Kim, S., Griffith, M., et al., 2015. U2AF1 mutations alter sequence specificity of pre-mRNA binding and splicing. Leukemia. 29, 909-917.

Pan, Q., Shai, O., Lee, L.J., Frey, B.J., Blencowe, B.J., 2008. Deep surveying of alternative splicing complexity in the human transcriptome by high-throughput sequencing. Nat Genet. 40, 1413-1415.

Papaemmanuil, E., Cazzola, M., Boultwood, J., Malcovati, L., Vyas, P., Bowen, D., et al., 2011. Somatic SF3B1 mutation in myelodysplasia with ring sideroblasts. N Engl J Med. $365,1384-1395$.

Papaemmanuil, E., Gerstung, M., Malcovati, L., Tauro, S., Gundem, G., Van Loo, P., et al., 2013. Clinical and biological implications of driver mutations in myelodysplastic syndromes. Blood. 122, 3616-3627; quiz 3699.

Paradkar, P.N., Zumbrennen, K.B., Paw, B.H., Ward, D.M., Kaplan, J., 2009. Regulation of mitochondrial iron import through differential turnover of mitoferrin 1 and mitoferrin 2 . Mol Cell Biol. 29, 1007-1016.

Park, S.M., Ou, J., Chamberlain, L., Simone, T.M., Yang, H., Virbasius, C.M., et al., 2016. U2AF35(S34F) Promotes Transformation by Directing Aberrant ATG7 Pre-mRNA 3' End Formation. Mol Cell. 62, 479-490.

Patnaik, M.M., Lasho, T.L., Finke, C.M., Hanson, C.A., Hodnefield, J.M., Knudson, R.A., et al., 2013. Spliceosome mutations involving SRSF2, SF3B1, and U2AF35 in chronic 
myelomonocytic leukemia: prevalence, clinical correlates, and prognostic relevance. Am J Hematol. 88, 201-206.

Patnaik, M.M., Lasho, T.L., Hodnefield, J.M., Knudson, R.A., Ketterling, R.P., GarciaManero, G., et al., 2012. SF3B1 mutations are prevalent in myelodysplastic syndromes with ring sideroblasts but do not hold independent prognostic value. Blood. 119, 569-572.

Pellagatti, A., Boultwood, J., 2015. The molecular pathogenesis of the myelodysplastic syndromes. Eur J Haematol. 95, 3-15.

Pellagatti, A., Boultwood, J., 2017. Splicing factor gene mutations in the myelodysplastic syndromes: impact on disease phenotype and therapeutic applications. Adv Biol Regul. 63, 59-70.

Pellagatti, A., Roy, S., Di Genua, C., Burns, A., McGraw, K., Valletta, S., et al., 2016. Targeted resequencing analysis of 31 genes commonly mutated in myeloid disorders in serial samples from myelodysplastic syndrome patients showing disease progression. Leukemia. 30, 247-250.

Pellagatti, A., Steeples, V., Sharma, E., Repapi, E., Radujkovic, A., Horn, P., et al., 2017. Identification of aberrantly spliced genes and deregulated pathways/gene ontology themes in myelodysplastic syndrome patients with splicing factor gene mutations. Leuk Res. 55, S9.

Pondarre, C., Campagna, D.R., Antiochos, B., Sikorski, L., Mulhern, H., Fleming, M.D., 2007. Abcb7, the gene responsible for X-linked sideroblastic anemia with ataxia, is essential for hematopoiesis. Blood. 109, 3567-3569.

Przychodzen, B., Jerez, A., Guinta, K., Sekeres, M.A., Padgett, R., Maciejewski, J.P., et al., 2013. Patterns of missplicing due to somatic U2AF1 mutations in myeloid neoplasms. Blood. 122, 999-1006.

Quesada, V., Conde, L., Villamor, N., Ordóñez, G.R., Jares, P., Bassaganyas, L., et al., 2011. Exome sequencing identifies recurrent mutations of the splicing factor SF3B1 gene in chronic lymphocytic leukemia. Nat Genet. 44, 47-52.

Rose, D., Haferlach, T., Kern, W., Haferlach, C., 2015. Categorizing Molecular Mutations in MDS and AML. Blood. 126, 5222.

Ruskin, B., Zamore, P.D., Green, M.R., 1988. A factor, U2AF, is required for U2 snRNP binding and splicing complex assembly. Cell. 52, 207-219.

Saez, B., Walter, M.J., Graubert, T.A., 2017. Splicing factor gene mutations in hematologic malignancies. Blood. 129, 1260-1269.

Sakai, T., Asai, N., Okuda, A., Kawamura, N., Mizui, Y., 2004a. Pladienolides, new substances from culture of Streptomyces platensis Mer-11107. II. Physico-chemical properties and structure elucidation. J Antibiot (Tokyo). 57, 180-187.

Sakai, T., Sameshima, T., Matsufuji, M., Kawamura, N., Dobashi, K., Mizui, Y., 2004b. Pladienolides, new substances from culture of Streptomyces platensis Mer-11107. I. Taxonomy, fermentation, isolation and screening. J Antibiot (Tokyo). 57, 173-179.

Sakai, Y., Tsujita, T., Akiyama, T., Yoshida, T., Mizukami, T., Akinaga, S., et al., 2002a. GEX1 compounds, novel antitumor antibiotics related to herboxidiene, produced by Streptomyces sp. II. The effects on cell cycle progression and gene expression. J Antibiot (Tokyo). 55, 863-872.

Sakai, Y., Yoshida, T., Ochiai, K., Uosaki, Y., Saitoh, Y., Tanaka, F., et al., 2002b. GEX1 compounds, novel antitumor antibiotics related to herboxidiene, produced by Streptomyces sp. I. Taxonomy, production, isolation, physicochemical properties and biological activities. J Antibiot (Tokyo). 55, 855-862.

Santini, V., 2017. First-line Therapeutic Strategies for Myelodysplastic Syndromes. Clin Lymphoma Myeloma Leuk. 17S, S31-S36. 
Sashida, G., Harada, H., Matsui, H., Oshima, M., Yui, M., Harada, Y., et al., 2014. Ezh2 loss promotes development of myelodysplastic syndrome but attenuates its predisposition to leukaemic transformation. Nat Commun. 5, 4177.

Schaal, T.D., Maniatis, T., 1999. Multiple distinct splicing enhancers in the protein-coding sequences of a constitutively spliced pre-mRNA. Mol Cell Biol. 19, 261-273.

Scotti, M.M., Swanson, M.S., 2016. RNA mis-splicing in disease. Nat Rev Genet. 17, 19-32.

Seki-Asano, M., Okazaki, T., Yamagishi, M., Sakai, N., Takayama, Y., Hanada, K., et al., 1994. Isolation and characterization of a new 12-membered macrolide FD-895. J Antibiot (Tokyo). 47, 1395-1401.

Shen, H., Zheng, X., Luecke, S., Green, M.R., 2010. The U2AF35-related protein Urp contacts the 3' splice site to promote U12-type intron splicing and the second step of U2type intron splicing. Genes Dev. 24, 2389-2394.

Shi, Y., Joyner, A.S., Shadrick, W., Palacios, G., Lagisetti, C., Potter, P.M., et al., 2015. Pharmacodynamic assays to facilitate preclinical and clinical development of pre-mRNA splicing modulatory drug candidates. Pharmacol Res Perspect. 3, e00158.

Shiozawa, Y., Malcovati, L., Sato-Otsubo, A., Gallì, A., Yoshida, K., Yoshizato, T., et al., 2015. Different Mutant Splicing Factors Cause Distinct Missplicing Events and Give Rise to Different Clinical Phenotypes in Myelodysplastic Syndromes. Blood. 126, 139.

Shirai, C.L., Ley, J.N., White, B.S., Kim, S., Tibbitts, J., Shao, J., et al., 2015. Mutant U2AF1 Expression Alters Hematopoiesis and Pre-mRNA Splicing In Vivo. Cancer Cell. 27, 631643.

Shirai, C.L., White, B.S., Tripathi, M., Tapia, R., Ley, J.N., Ndonwi, M., et al., 2017. Mutant U2AF1-expressing cells are sensitive to pharmacological modulation of the spliceosome. Nat Commun. 8, 14060.

Steelman, L.S., Franklin, R.A., Abrams, S.L., Chappell, W., Kempf, C.R., Bäsecke, J., et al., 2011. Roles of the Ras/Raf/MEK/ERK pathway in leukemia therapy. Leukemia. 25, 10801094.

Steensma, D.P., 2015. Myelodysplastic Syndromes: Diagnosis and Treatment. Mayo Clin Proc. 90, 969-983.

Steensma, D.P., Maris, M.B., Yang, J., Donnellan, W.B., Brunner, A.M., McMasters, M., et al., 2017. H3B-8800-G0001-101: A first in human phase I study of a splicing modulator in patients with advanced myeloid malignancies. J Clin Oncol. 35, TPS7075.

Stein, C.A., Castanotto, D., 2017. FDA-Approved Oligonucleotide Therapies in 2017. Mol Ther. 25, 1069-1075.

Tefferi, A., Vardiman, J.W., 2009. Myelodysplastic syndromes. N Engl J Med. 361, 18721885.

Teng, T., Tsai, J.H., Puyang, X., Seiler, M., Peng, S., Prajapati, S., et al., 2017. Splicing modulators act at the branch point adenosine binding pocket defined by the PHF5A-SF3b complex. Nat Commun. 8, 15522.

Thol, F., Kade, S., Schlarmann, C., Loffeld, P., Morgan, M., Krauter, J., et al., 2012. Frequency and prognostic impact of mutations in SRSF2, U2AF1, and ZRSR2 in patients with myelodysplastic syndromes. Blood. 119, 3578-3584.

Tronchère, H., Wang, J., Fu, X.D., 1997. A protein related to splicing factor U2AF35 that interacts with U2AF65 and SR proteins in splicing of pre-mRNA. Nature. 388, 397-400.

Turunen, J.J., Niemelä, E.H., Verma, B., Frilander, M.J., 2013. The significant other: splicing by the minor spliceosome. Wiley Interdiscip Rev RNA. 4, 61-76.

van Deutekom, J.C., Janson, A.A., Ginjaar, I.B., Frankhuizen, W.S., Aartsma-Rus, A., Bremmer-Bout, M., et al., 2007. Local dystrophin restoration with antisense oligonucleotide PRO051. N Engl J Med. 357, 2677-2686. 
Villa, R., Mandel, A.L., Jones, B.D., La Clair, J.J., Burkart, M.D., 2012. Structure of FD-895 revealed through total synthesis. Org Lett. 14, 5396-5399.

Visconte, V., Avishai, N., Mahfouz, R., Tabarroki, A., Cowen, J., Sharghi-Moshtaghin, R., et al., 2015. Distinct iron architecture in SF3B1-mutant myelodysplastic syndrome patients is linked to an SLC25A37 splice variant with a retained intron. Leukemia. 29, 188-195.

Visconte, V., Rogers, H.J., Singh, J., Barnard, J., Bupathi, M., Traina, F., et al., 2012. SF3B1 haploinsufficiency leads to formation of ring sideroblasts in myelodysplastic syndromes. Blood. 120, 3173-3186.

Walter, M.J., Shen, D., Shao, J., Ding, L., White, B.S., Kandoth, C., et al., 2013. Clonal diversity of recurrently mutated genes in myelodysplastic syndromes. Leukemia. 27, 12751282.

Wang, C., Sashida, G., Saraya, A., Ishiga, R., Koide, S., Oshima, M., et al., 2014. Depletion of Sf3b1 impairs proliferative capacity of hematopoietic stem cells but is not sufficient to induce myelodysplasia. Blood. 123, 3336-3343.

Webb, T.R., Joyner, A.S., Potter, P.M., 2013. The development and application of small molecule modulators of SF3b as therapeutic agents for cancer. Drug Discov Today. 18, 43-49.

Wittrup, A., Lieberman, J., 2015. Knocking down disease: a progress report on siRNA therapeutics. Nat Rev Genet. 16, 543-552.

Wojtuszkiewicz, A., Assaraf, Y.G., Jansen, G., Koide, K., Bressin, R.K., Basu, U., et al., 2014. Spliceosome Inhibitor Meayamycin B As a Novel Potential Chemotherapeutic Agent in ALL and AML. Blood. 124, 924.

Wu, L., Song, L., Xu, L., Chang, C., Xu, F., Wu, D., et al., 2016. Genetic landscape of recurrent ASXL1, U2AF1, SF3B1, SRSF2, and EZH2 mutations in 304 Chinese patients with myelodysplastic syndromes. Tumour Biol. 37, 4633-4640.

Wu, S., Romfo, C.M., Nilsen, T.W., Green, M.R., 1999. Functional recognition of the 3' splice site AG by the splicing factor U2AF35. Nature. 402, 832-835.

Wu, S.J., Kuo, Y.Y., Hou, H.A., Li, L.Y., Tseng, M.H., Huang, C.F., et al., 2012. The clinical implication of SRSF2 mutation in patients with myelodysplastic syndrome and its stability during disease evolution. Blood. 120, 3106-3111.

Wu, S.J., Tang, J.L., Lin, C.T., Kuo, Y.Y., Li, L.Y., Tseng, M.H., et al., 2013. Clinical implications of U2AF1 mutation in patients with myelodysplastic syndrome and its stability during disease progression. Am J Hematol. 88, E277-282.

Wulfert, M., Küpper, A.C., Tapprich, C., Bottomley, S.S., Bowen, D., Germing, U., et al., 2008. Analysis of mitochondrial DNA in 104 patients with myelodysplastic syndromes. Exp Hematol. 36, 577-586.

Xargay-Torrent, S., López-Guerra, M., Rosich, L., Montraveta, A., Roldán, J., Rodríguez, V., et al., 2015. The splicing modulator sudemycin induces a specific antitumor response and cooperates with ibrutinib in chronic lymphocytic leukemia. Oncotarget. 6, 22734-22749.

Yien, Y.Y., Robledo, R.F., Schultz, I.J., Takahashi-Makise, N., Gwynn, B., Bauer, D.E., et al., 2014. TMEM14C is required for erythroid mitochondrial heme metabolism. J Clin Invest. 124, 4294-4304.

Yip, B.H., Dolatshad, H., Roy, S., Pellagatti, A., Boultwood, J., 2016. Impact of Splicing Factor Mutations on Pre-mRNA Splicing in the Myelodysplastic Syndromes. Curr Pharm Des. 22, 2333-2344.

Yip, B.H., Steeples, V., Repapi, E., Armstrong, R.N., Llorian, M., Roy, S., et al., 2017. The U2AF1S34F mutation induces lineage-specific splicing alterations in myelodysplastic syndromes. J Clin Invest. 127, 2206-2221.

Yoshida, K., Sanada, M., Shiraishi, Y., Nowak, D., Nagata, Y., Yamamoto, R., et al., 2011. Frequent pathway mutations of splicing machinery in myelodysplasia. Nature. 478, 64-69. 
Zhang, J., Lieu, Y.K., Ali, A.M., Penson, A., Reggio, K.S., Rabadan, R., et al., 2015a. Disease-associated mutation in SRSF2 misregulates splicing by altering RNA-binding affinities. Proc Natl Acad Sci U S A. 112, E4726-4734.

Zhang, L., Padron, E., Lancet, J., 2015b. The molecular basis and clinical significance of genetic mutations identified in myelodysplastic syndromes. Leuk Res. 39, 6-17.

Zhou, Q., Derti, A., Ruddy, D., Rakiec, D., Kao, I., Lira, M., et al., 2015. A chemical genetics approach for the functional assessment of novel cancer genes. Cancer Res. 75, 1949-1958. 
Table 1. Characteristics of splicing inhibitors targeting the SF3b complex.

\begin{tabular}{|c|c|c|c|c|}
\hline Inhibitors & Origin & Splicing inhibition properties & Cellular effects & Clinical Trials \\
\hline $\begin{array}{c}\text { FR901464 } \\
\text { (FR901464 } \\
\text { family) }\end{array}$ & $\begin{array}{l}\text { Isolated from Pseudomonas sp } \\
\text { (Kaida et al., 2007). }\end{array}$ & $\begin{array}{l}\text { Arrests spliceosome assembly } \\
\text { at complex A (Liu et al., } \\
\text { 2013a). }\end{array}$ & $\begin{array}{c}\text { Anticancer property. Causes cell cycle } \\
\text { arrest at G1 and G2/M phase (Kaida et } \\
\text { al., 2007). }\end{array}$ & - \\
\hline $\begin{array}{l}\text { Spliceostatin A } \\
\text { (FR901464 } \\
\text { family) }\end{array}$ & $\begin{array}{l}\text { Methoxy and more stable form } \\
\text { of FR901464 (Kaida et al., } \\
\text { 2007; Liu et al., 2013a). }\end{array}$ & $\begin{array}{l}\text { Destabilizes U2 snRNP-pre- } \\
\text { mRNA complexes and blocks } \\
\text { subsequent spliceosome } \\
\text { assembly (Complex A to B) } \\
\text { (Bonnal et al., 2012). }\end{array}$ & Antitumor activity (Kaida et al., 2007). & - \\
\hline $\begin{array}{l}\text { Thailanstatin } \\
\text { (A, B and C) } \\
\text { (FR901464 } \\
\text { family) }\end{array}$ & $\begin{array}{l}\text { Natural and more stable } \\
\text { analogues of FR901464. } \\
\text { Isolated from Burkholderia } \\
\text { thailandensis MSMB43 (Liu et } \\
\text { al., 2013a; Liu et al., 2013b). }\end{array}$ & $\begin{array}{l}\text { Arrests spliceosome assembly } \\
\text { at complex A (Liu et al., } \\
\text { 2013a). }\end{array}$ & $\begin{array}{l}\text { Strong antiproliferative activity in human } \\
\text { cancer cell lines (Martinez-Montiel et al., } \\
\text { 2016). }\end{array}$ & - \\
\hline $\begin{array}{l}\text { Meayamycin } \\
\text { (FR901464 } \\
\text { family) }\end{array}$ & $\begin{array}{c}\text { Methylated, more stable } \\
\text { synthetic analogue of } \\
\text { FR901464 (Albert et al., 2009). }\end{array}$ & $\begin{array}{l}\text { Blocks assembly of complex A } \\
\text { (Albert et al., 2009). }\end{array}$ & $\begin{array}{l}\text { Meayamycin B inhibits the growth of } \\
\text { AML and ALL cell lines } \\
\text { (Wojtuszkiewicz et al., 2014). }\end{array}$ & - \\
\hline $\begin{array}{c}\text { E7107 } \\
\text { (Pladienolides) }\end{array}$ & $\begin{array}{c}\text { Semisynthetic } \\
\text { cycloheptylpiperazine- } \\
\text { containing derivative of } \\
\text { Pladienolides B and D (Dehm, } \\
\text { 2013). }\end{array}$ & $\begin{array}{l}\text { Blocks the interaction of U2 } \\
\text { snRNP with the branch point in } \\
\text { pre-mRNAs and stalls } \\
\text { spliceosome assembly at } \\
\text { complex A (Dehm, 2013). }\end{array}$ & $\begin{array}{c}\text { Induces apoptosis and cell cycle arrest at } \\
\text { G1-G2-M. Strongly inhibits cell } \\
\text { proliferation and has anti-cancer activity } \\
\text { (Eskens et al., 2013). Preferential } \\
\text { sensitivity of SRSF2 mutant cells to } \\
\text { E7107 in vitro and in vivo (Lee et al., } \\
\text { 2016). }\end{array}$ & $\begin{array}{c}\text { Phase I Clinical Trials } \\
\text { (NCT00459823 and } \\
\text { NCT00499499) to patients } \\
\text { with solid tumours. } \\
\text { However, the trials were } \\
\text { suspended due to vision loss } \\
\text { in some patients (Hong et } \\
\text { al., 2014; Webb et al., 2013) }\end{array}$ \\
\hline $\begin{array}{l}\text { Pladienolide B } \\
\text { (Pladienolides) }\end{array}$ & $\begin{array}{l}\text { Polyketide originally isolated } \\
\text { from Streptomyces platensis } \\
\text { (Eskens et al., 2013). }\end{array}$ & $\begin{array}{l}\text { Stalls spliceosome assembly at } \\
\text { complex A (Eskens et al., } \\
\text { 2013). }\end{array}$ & $\begin{array}{l}\text { Induces apoptosis in CLL cells (Kashyap } \\
\text { et al., 2012). }\end{array}$ & - \\
\hline $\begin{array}{l}\text { Sudemycins } \\
(\mathrm{C} 1, \mathrm{D} 1, \mathrm{D} 6, \mathrm{E}, \\
\mathrm{F} 1, \mathrm{~F} 2, \mathrm{~K})\end{array}$ & $\begin{array}{l}\text { Chemically stable synthetic } \\
\text { compounds derived from } \\
\text { FR901464 and Pladienolide } \\
\quad \text { (Fan et al., 2011). }\end{array}$ & $\begin{array}{l}\text { Sudemycin E causes } \\
\text { dissociation of U2 snRNP and } \\
\text { reduces its interaction with } \\
\text { nucleosomes (Convertini et al., } \\
\text { 2014). }\end{array}$ & $\begin{array}{l}\text { Preferential sensitivity of } U 2 A F 1 \text { mutant } \\
\text { cells to Sudemycin D6 in vitro and in vivo } \\
\text { (Shirai et al., 2017). }\end{array}$ & $\begin{array}{c}\text { Sudemycin D6 is currently } \\
\text { in Preclinical development } \\
\text { (Lagisetti et al., 2013; Shi et } \\
\text { al., 2015). }\end{array}$ \\
\hline
\end{tabular}




\begin{tabular}{|c|c|c|c|c|}
\hline $\begin{array}{l}\text { Herboxidiene } \\
\text { (GEX1A) }\end{array}$ & $\begin{array}{l}\text { Polyketide natural product. } \\
\text { Secondary metabolite of } \\
\text { bacteria. Originally isolated } \\
\text { from Streptomyces } \\
\text { chromofuscus } \text { strain A7847 } \\
\text { (Lagisetti et al., 2014). }\end{array}$ & $\begin{array}{c}\text { Arrests spliceosome assembly } \\
\text { at complex A (Effenberger et } \\
\text { al., 2014; Effenberger et al., } \\
\text { 2017). }\end{array}$ & $\begin{array}{c}\text { Cytotoxic to various human cancer cell } \\
\text { lines (Lagisetti et al., 2014). It also } \\
\text { possesses several biological activities, } \\
\text { including antiangiogenic and anti- } \\
\text { cholesterol activity (Jung et al., 2015). } \\
\text { Causes G1 and G2/M cell cycle arrest } \\
\text { (Sakai et al., 2002a). }\end{array}$ & - \\
\hline H3B-8800 & $\begin{array}{l}\text { Orally bioavailable splicing } \\
\text { modulator (Buonamici et al., } \\
\text { 2016). }\end{array}$ & Not described. & $\begin{array}{l}\text { Preferential sensitivity of } S F 3 B 1 \text { and } \\
\text { SRSF2 mutant cells to H3B-8800 in vitro } \\
\text { and in vivo (Buonamici et al., 2016). }\end{array}$ & $\begin{array}{c}\text { Phase I clinical trial } \\
\text { (NCT02841540) in patients } \\
\text { with MDS, AML and } \\
\text { CMML (Buonamici et al., } \\
\text { 2016; Steensma et al., 2017) }\end{array}$ \\
\hline FD-895 & $\begin{array}{c}\text { Bioactive polyketide and } \\
\text { natural products of } \\
\text { Streptomyces sp (Eskens et al., } \\
\text { 2013). }\end{array}$ & $\begin{array}{l}\text { Arrests spliceosome assembly } \\
\text { at complex A (Effenberger et } \\
\text { al., 2017; Kashyap et al., 2012). }\end{array}$ & Same as Pladienolide B. & - \\
\hline
\end{tabular}


Figure 1. Mechanisms of action of antisense oligonucleotides. A. Antisense oligonucleotide (ASO) binds to a unique region in the spliced mRNA and directs RNase H-mediated degradation. B. Splice-switching oligonucleotides (SSO) bind and block exonic splicing enhancers (ESE) and/or intronic splicing enhancers (ISE) promoting exon skipping. C. SSO bind and block exonic splicing silencers (ESS) and/or intronic splicing silencers (ISS) promoting exon inclusion. D. SSO bind and block recognition of cryptic splice sites by the splicing machinery. 